\title{
Microarray Evidences the Role of Pathologic Adipose Tissue in Insulin Resistance and Their Clinical Implications
}

\author{
Sandeep Kumar Mathur, ${ }^{1}$ Priyanka Jain, ${ }^{2}$ and Prashant Mathur ${ }^{3}$ \\ ${ }^{1}$ Department of Endocrinology, S. M. S. Medical College, India \\ ${ }^{2}$ Institute of Genomics and Integrative Biology, Mall Road, New Delhi 110007, India \\ ${ }^{3}$ Department of Pharmacology, S. M. S. Medical College, J. L. Marg, Jaipur 302004, India
}

Correspondence should be addressed to Sandeep Kumar Mathur, drsandeepmathur@rediffmail.com

Received 1 December 2010; Accepted 21 February 2011

Academic Editor: Eliot Brinton

Copyright (C) 2011 Sandeep Kumar Mathur et al. This is an open access article distributed under the Creative Commons Attribution License, which permits unrestricted use, distribution, and reproduction in any medium, provided the original work is properly cited.

\begin{abstract}
Clustering of insulin resistance and dysmetabolism with obesity is attributed to pathologic adipose tissue. The morphologic hallmarks of this pathology are adipocye hypertrophy and heightened inflammation. However, it's underlying molecular mechanisms remains unknown. Study of gene function in metabolically active tissues like adipose tissue, skeletal muscle and liver is a promising strategy. Microarray is a powerful technique of assessment of gene function by measuring transcription of large number of genes in an array. This technique has several potential applications in understanding pathologic adipose tissue. They are: (1) transcriptomic differences between various depots of adipose tissue, adipose tissue from obese versus lean individuals, high insulin resistant versus low insulin resistance, brown versus white adipose tissue, (2) transcriptomic profiles of various stages of adipogenesis, (3) effect of diet, cytokines, adipokines, hormones, environmental toxins and drugs on transcriptomic profiles, (4) influence of adipokines on transcriptomic profiles in skeletal muscle, hepatocyte, adipose tissue etc., and (5) genetics of gene expression. The microarray evidences of molecular basis of obesity and insulin resistance are presented here. Despite the limitations, microarray has potential clinical applications in finding new molecular targets for treatment of insulin resistance and classification of adipose tissue based on future risk of insulin resistance syndrome.
\end{abstract}

\section{Introduction}

The term insulin resistance means impairment in insulin action at its target organs [1]. This biochemical defect is commonly seen in subjects with visceral obesity, and it clusters with modern life diseases like type-2 diabetes mellitus, hypertension, dylipidemia and atherosclerotic vascular disease [2-4]. This association was initially demonstrated in clinical studies, and subsequently epidemiological studies done across the globe have generated convincing evidences to support this association [5-8]. Increasing adipose tissue mass was found to be associated with altered fat metabolism and inflammation, thus contributing to diabetes and vascular disease. This association is recognized clinically as metabolic syndrome. However, questions have been raised on existence of metabolic syndrome as a distinct disease because its pathophysiology is still not well defined [9-13].
Recently, the concept of "adiposopathy" has been, suggested to define this cluster of obesity, inflammation and metabolic/vascular complications as a formal disease [1416]. The basic assumption is that occurrence of diabetes and other metabolic problems are related to both quantity and quality of fat and this fat has unique cellular and molecular pathology. Its precise etiology is unknown but expected to have a genetic component and is complex, that is, contributed by both hereditary and environmental factors $[17,18]$. Some racial groups like Pima Indians and Asian Indians have strong genetic factor in their increased susceptibility to develop diabetes [19-22]. Identification of this genetic component is pursued intensively and is on lines of strategy recommended for any complex trait [2326]. The cornerstone of this complex genetic trait dissection is genomewide association of clinical phenotypes as well as gene function [27]. Microarray is a powerful technique of 
assessment of expression of genes in a tissue at any time at genomewide scale and has been applied in understanding role of adipose tissue in insulin resistance [28-31]. The clinical implications of these microarray evidences and the insight gained into the understanding adiposopathy are presented here.

\section{Overview of the Concept of Pathologic Adipose Tissue and Its Role in Insulin Resistance}

The hallmark pathologic feature of adiposopathy is adipocyte hypertrophy [32-34] and visceral deposition [35-42]. The other features are adipose tissue macrophage [43, 44], possibly lymphocytic infiltration [45], poor angiogenesis $[46,47]$, intercellular matrix defects [48-50] and "cross talk" that is, fat deposition in other organs like liver, muscle, pancreatic beta cells, and so forth, [51-53]. Adipose tissue is not only the largest endocrine organ of the body but has unique ability to adapt its size in response to calorie excess. The initial compensation is adipocyte hypertrophy but with continued fat deposition there is recruitment of committed mesothelial stem cell progenitors of preadipocytes [54]. Their proliferation leads to formation of small adipocytes which are metabolically efficient in storing excess fat. This adipocyte proliferation is called adipogenesis. Impairment in adipogenesis leads to further adipocyte hypertrophy. These hypertrophied cells have imbalance in lipid synthesis (lipogenesis) and breakdown (lipolysis) and overexpress free fatty acid flux. This heightened FFA flux play an important role in insulin resistance and other metabolic defects of obesity $[55,56]$.

Increasing adipose tissue mass has also been found to be associated with macrophage infiltration [57]. It is seen in both genetic and nutritional animal models of obesity as well as in human obesity. These macrophages secrete a large number of cytokines like TNF- $\alpha$, IL-1, IL-6, and so forth, [58, 59]. These infiltrating macrophages are of two types M1and M2. The phenotypic switch from M2 to M1 is possibly an important determinant of insulin resistance [60]. Recently CD $11 c^{+}$macrophages were found to be the marker of insulin resistance in human obesity [61]. This inflammatory state of adipose tissue plays an important role in insulin resistance $[62,63]$. Adipocyte hypertrophy itself was also found to be associated macrophage infiltration and heightened cytokine/adipokine secretion and inflammation $[64,65]$.

\section{Relevance and Power of Microarray: The Evidences Required to Support Concept of Pathologic Adipose Tissue}

The term microarray represents an array of large number of microscopic spots on a solid surface $[66,67]$. The solid surface could be a glass slide or nylon membrane or quartz wafer. These spots could be of complementary cDNA (cDNA microarray), oligonucleotide probes (high density oligonucleotide microarray), protein (protein array), or microRNA
(microRNA microarray). Presence of a large number of spots on one slide (which could be of even genomewide scale for DNA chip) and their ability to hybridize with its complementary sequence in the target sample with high precision gives this technology the power of genomewide study in single experiment. Because of these advantages this technology is presently the most frequently used technique for the study complex molecular functions in a cell [68].

Because DNA microarrays simultaneously measure expression of thousands of genes in a given cell at a given point, therefore information gained from these studies can generate working hypothesis for molecular pathways essential to a given biologic process. These transcriptomic profiles depend on the cell type, genotype, and environment of the cell. Therefore it can be applied for the study of following aspects of adiposopathy [69]. First, to find the transcriptomic differences between various depots of adipose tissue, adipose tissue from obese versus lean individuals, high insulin resistance versus low insulin resistance, and brown versus white adipose tissue. Second, to see transcriptomic profiles of various stages of adipogenesis, that is, transcription control of adipogenesis. Third, to see effect of factors like diet, cytokines, adipokines, hormones, environmental toxins and drugs on transcriptomic profiles. Fourth, to see the influence of adipokines on transcriptomic profiles in skeletal muscle, hepatocyte, adipose tissue, and so forth. Fifth, to find genetics of gene expression, that is, integration of gene expression phenotypes with genomewide association. Sixth, the assessment of adipose tissue transcription control by study of genomewide gene methylation studies and microRNA by microarray.

The other potential applications of microarray are: study of gene sequence variation by typing of SNPs and copy number variation by using SNP arrays.

\section{Obesity and Inflammation: The Microarray Evidences}

Several human and animal model studies have compared adipose tissue gene expression profiles of obese and lean individuals [31,70-75]. A large number of genes representing various molecular functions and pathways were found to be differentially expressed in adipose tissue of obese subject. Most of these genes were found to be in the molecular pathways of adipose tissue inflammation, lipid and carbohydrate metabolism, adipogenesis and cytoskeletal structure regulation and so forth. However, the most of the genes identified in any studies could not be replicated in subsequent studies. It could be because of several reasons like genetic differences in study population, disease heterogeneity, and nonuniform physiologic condition at time of sampling and method of sampling. But it is important to note that gene expression profiling was found to be altered with obesity in almost all studies. This suggests that increase in adipose tissue mass is not merely a quantitative change, but it also alters its quality, therefore supports the concept of adiposopathy. 
Increasing adipose tissue mass was found to be associated with upregulation of inflammation-related genes in almost all studies [76]. When the stromal-vascular fraction of adipose tissue was separated from adipocytes, the inflammation-related genes were upregulated in stromal fraction $[77,78]$. These findings suggest that the inflammatory state of adipose tissue is predominantly because of infiltrating macrophages. These macrophages secrete a large number of inflammatory cytokines like TNF- $\alpha$, IL-6, IL-1, and so forth, $[58,59]$. In fact microarray evidences also support the histology findings of increased macrophage infiltration in adipose tissue in obesity. However it is worth mentioning here that adipocytes, when cultured isolated even then showed upregulation of inflammation-related genes. Though the relative contribution of adipocytes in overall systemic inflammation of obesity is much less as compared with macrophages, but their precise role in initiation of inflammatory seems to be very important. The current evidences suggest that adipocyte hypertrophy is associated with increased release of TNF- $\alpha$, an inflammatory state [79]. These cytokines plays an important role in lymphocyte and macrophage infiltration in the adipose tissue and further augmentation of inflammation by heightened cytokine release. A vicious cycle is generated as adipokines released from infiltrating macrophages impairs adipogenesis, and augments free fatty acid/cytokine release from hypertrophied adipocytes. Diabetics in one study were found to have not only much higher FFA level and insulin resistance than BMI-matched controls, but also showed positive correlation between them [80]. The vicious cycle of augmented inflammation in adipose tissue could be the underlying mechanism of this finding.

Some recent studies examined effect of inflammatory factors on adipocytes. Shah et al. [81] applied microarray mRNA profiling of human adipose during endotoxemia to identify novel inflammation-induced adipose tissue genes. Several genes implicated inflammation, but not known to be expressed in adipose tissue were upregulated in response to induced inflammation. These findings suggest that induced inflammation further augments inflammation of obesity.

Obesity was found to be associated with recruitment of lymphocytes [82-84] and increased expression of inflammation-related genes from M1 macrophages [85-87]. These infiltrating cells play an important role in inflammation of obesity.

Apart from inducing inflammation, infiltrating macrophages also influence remodeling of adipose tissue. O'Hara et al. [88] treated human adipocytes in culture with macrophage conditioned medium. Microarray analysis identified 1,088 genes differentially expressed in response to the conditioned medium at both 4 and $24 \mathrm{~h}$ (754 upregulated, 334 downregulated at $24 \mathrm{~h}$ ); these included genes associated with inflammation and macrophage infiltration. A cluster of matrix metalloproteinase genes were highly upregulated at both time points, including MMP1, MMP3, MMP9, MMP10, MMP12 and MMP19. At 4 and 24h, MMP1 was the most highly upregulated gene $(>2,400$-fold increase in mRNA at $24 \mathrm{~h}$ ). ELISA measurements indicated that substantial quantities of MMP1 and MMP3 were released from adipocytes incubated with conditioned medium, with little release by control adipocytes. Treatment with TNFalpha induced substantial increases in MMP1 (>100-fold) and MMP3 (27-fold) mRNA level as well as MMP1 and MMP3 release in adipocytes, suggesting that this cytokine could contribute to the stimulation of MMP expression by macrophages, thus contributing to tissue remodeling during adipose tissue expansion in obesity.

Though there are convincing evidences for the role of macrophages in adipose tissue inflammation, the precise cause of their infiltration in the adipose tissue is still not known. However several hypotheses have been suggested. They are as follow (1) increasing adipose tissue mass not accompanied by increase in its vascularity leads to local hypoxia, which is the cause of macrophage infiltration [8992], (2) obesity is associated with increased expression of chemokines like monocyte chemoattractant protein (MCP)1, MCP-3, macrophage inflammatory protein (MIP)- $1 \alpha$, and they play an important role in macrophage infiltration [9397] (3) increasing adiposity is associated with elevated leptin levels and later increases adhesion molecule expression in endothelial cells and monocyte diapedesis $[98,99]$, and $(4)$ as adipocytes share several characters with immune cells, it has also been suggested that preadipocytes are transdifferentiated into macrophages [98].

There is also possible role of epigenetic factors in adipose tissue inflammation. Epigenetic modifications are chemical additions to DNA and histones that are associated with changes in gene expression and are heritable but do not alter the primary DNA sequence. DNA methylation is one of the epigenetic modification and in mammals may be associated with gene silencing. The role of epigenetic factors in inflammation of obesity was suggested in transgenic mice overexpressing DNA methyltransferase (Dnmt3a). Gene expression levels of inflammatory cytokines such as tumor necrosis factor-alpha (TNF-alpha) and monocyte chemoattractant protein-1 (MCP-1) were higher in Dnmt3a mice than in wild-type mice on a high-fat diet. This study suggests that increased expression of Dnmt3a in the adipose tissue may contribute to obesity-related inflammation. However there are no human studies to support these findings [100].

\section{Adipogenesis Defects in Pathologic Adipose Tissue: The Role of Transcriptional Factors}

The pathologic hallmark of adiposopathy is adipocyte hypertrophy and has been hypothesized to be due to defects in proliferation and differentiation of mesenchymal stem cells and preadipocytes into mature adipocytes, a process called adipogenesis [101]. Adipogenesis is a complicated process and had been extensively studied. Much progress has been made in the last two decades in defining transcriptional events controlling the differentiation of mesenchymal stem cells into adipocytes. A complex network of transcription factors and cell-cycle regulators, in concert with specific transcriptional coactivators and corepressors, respond to extracellular stimuli to activate or repress adipocyte differentiation [102]. PPAR- $\gamma$ and C/EBP- $\alpha$ are the major regulatory 
factors. Precise understanding of this process is expected to open avenues for discovery of new molecular targets for prevention of expansion of adipose tissue in obesity and its transformation from benign to pathologic tissue found in high insulin resistance conditions.

Microarray is one of the most powerful techniques for understanding the process of adipogenesis not only because of its ability to study molecular function at large scale in single experiment, but also because of its precision, sensitivity and specificity. Therefore, gene expression during various stages of adipogenesis has been extensively studied and the data so generated has been subjected to metaanalysis. There are more than 20 published reports on gene expression profiling during various stages of adipogenesis [103-125]. Most of these studies used different platforms and had inherent problems like different probes, annotations and probe sequences. Apart from the heterogeneity of platforms these studies also had heterogeneity in terms of model studied: in vitro murine cell lines in culture, animal models and human mesenchymal stem cell/preadipocyte in vitro culture models. However, an exhaustive analysis and comparison of commonly used microarray platforms by a multicenter consortium (MAQC) showed-contrary to earlier reports [126, 127]-acceptable concordance between the platforms [128]; however, there is a necessity for careful control of biological samples and close adherence to standard protocols.

A large number of genes identified by these microarray studies were found to be associated with adipocyte development. Some of them were further studied from point of view of understanding molecular mechanisms of adipogenesis. Few of them are as follows: firstly, several members of the Krüppel-like factor family have been implicated in adipogenesis [129]. In microarray studies, Klf4 was shown to function as an immediate early regulator of adipogenesis by inducing C/EBP- $\beta$ and is required for adipogenesis [129]. Klf6, Klf15 and Klf5 have been found to play a role in adipogenesis. Klf5 acts by transactivating PPAR- $\gamma$. The available evidences suggest that these factors function by recruiting different coactivators or repressors [102]. Secondly, microarray studies identified differential expression of zinc finger containing transcription factor Egr2 (Krox20) during adipogenesis. The expression of Egr2 is activated very early after induction of adipogenesis. It stimulates adipogenesis at least in part through activating C/EBP- $\beta$ by binding to its promoter [130]. Thirdly, expression profiles of adipogenesis have identified orphan nuclear receptor Nr4al (Nur77) as an early gene. But, there are conflicting reports on effects of its altered expression in adipogenesis [131-133]. Another nuclear hormone receptor involved in adipogenesis is Nr1h3 (LXRalpha). A broader role of Nr1h3 in regulation of metabolism in adipocytes was suggested and the effects of Wnt-signaling in adipocyte differentiation were studied in timed series microarray experiments of 3T3L1 cells and retroviral infected 3T3-L1 cells encoding Wnt1 [134]. It is known that liver $\mathrm{X}$ receptors (LXRs) regulate cholesterol and fatty acid metabolism in liver tissue and macrophages. Recently it was also shown that activated Nr1h3 stimulate adipocyte differentiation through induction of PPAR- $\gamma$ expression, but it is not required for adipocyte differentiation [135]. A nuclear receptor gene expression atlas during the differentiation of 3T3-L1 cells, assessed using qPCR, also showed the importance of other nuclear receptors such as the Nr2f2 (COUP-TF2) in adipogenesis [124]. Fourthly, the role of Ebf1 (O/E-1), a helix-loop helix transcription factor, was studied in adipocytes with microarray analysis of Ebf1 overexpression in NIH-3T3 cells [115]. Further experiments helped place Ebf1 within the known transcriptional cascade of adipogenesis [136]. By the year 2000, it was shown that Gata2 and Gata3 are specifically expressed in adipocyte precursors and their down regulation sets the stage for terminal differentiation [137]. This type of expression profile could be confirmed later on with microarray experiments. A role for transcriptional coregulators in the control of energy homeostasis could be shown by knockout of the corepressor Nrip1 (RIP140) in adipocytes [117].

Microarray studies have also identified a number of enzymes regulating adipogenesis. For example, Xanthine dehydrogenase (Xdh, XOR), Stearoyl-CoA desaturase (Scd1), adipose triglyceride lipase Pnpla2 (ATGL), and so forth. Apart from identification of various transcription factors and genes showing differential expression during adipogenesis, the other applications of microarray in understanding this process are: (1) understanding the regulation of expression of various genes, (2) influence of perturbation of these genes on adipocyte physiology, and (3) effects of various drugs, nutrients and so forth.

Methylation of cytosine and formation of 5-methylcytosine are the only covalent DNA modification known in vertebrates [138]. This epigenetic modification regulates gene expression. Horri et al. recently studied role of DNA methylation in control of insulin-induced adipogenesis in 3T3-L1 preadipocytes using a method called microarraybased integrated analysis of methylation by isoschizomers (MIAMI). The MIAMI revealed that Hpa II sites of exon 1 in a Rho guanine nucleotide exchange factor 19 (ARHGEF19; WGEF) gene were demethylated during adipocyte differentiation of 3T3-L1 cells. This study suggests that adipogenesis was regulated by WGEF expression through DNA methylation change [139]. However, Ocada et al have shown that the diet-induced upregulation of leptin, Mest/Peg1, and sFRP5 gene expression in WAT during the development of obesity in mice is not mediated directly by changes in DNA methylation [140].

MicroRNAs (miRNAs) are short noncoding RNA that posttranscriptionally regulates gene expression. Some miRNAs have been proposed to be associated with obesity. Nakanishi et al. [141] found the upregulation of miR-335 in obesity using microarray analysis for miRNA. Furthermore, miR-335 levels were closely correlated with expression levels of adipocyte differentiation markers such as PPARgamma, aP2, and FAS in 3T3-L1 adipocyte. These findings provide the first evidence that the upregulated expressions of miR335 in liver and WAT of obese mice might contribute to the pathophysiology of obesity. Sun et al. [142] also investigated whether micro RNA plays a role in adipogenesis. They performed microarray analysis to detect miRNA expression 
during 3T3-L1 preadipocyte differentiation. Several miRNAs, including let-7, were upregulated during 3T3-L1 adipogenesis. Ectopic introduction of let-7 into 3T3-L1 cells inhibited clonal expansion as well as terminal differentiation. The mRNA encoding high-mobility group AT-hook 2 (HMGA2), a transcription factor that regulates growth and proliferation in other contexts, was inversely correlated with let-7 levels during 3T3-L1 cell adipogenesis, and let-7 markedly reduced HMGA2 concentrations. Knockdown of HMGA2 inhibited 3T3-L1 differentiation. These results suggest that let-7 plays an important role in adipocyte differentiation and that it does so in part by targeting HMGA2, thereby regulating the transition from clonal expansion to terminal differentiation.

\section{Mechanism of Inflammation and High FFA Flux from Hypertrophied Adipocytes}

Adipose tissue is the major energy reservoir of the body. The excess calories resulting from energy imbalance are predominantly stored as triglycerides. About $95 \%$ of adipocyte mass consists of triglycerides. Fat content of an adipocyte (in other words size of an adipocyte) depends on balance between fat deposition (by either nutrient transport or fat synthesis by lipogenesis) and fat depletion (by either utilization in lipolysis or export out of cell). However this single cell fat balance must be differentiated from overall fat balance of the body, which in addition also depends on recruitment of newer adipocytes by adipogenesis. When the process of adipogenesis is insufficient size of an individual fat cell increases to accommodate excess calories deposited as lipids.

The lipid deposition in an adipocyte is regulated by the nutrients, hormones and perilipin family of lipid droplet coat proteins [143]. The process of lipogenesis is stimulated by excess of carbohydrates and inhibited by polyunsaturated fatty acids and fasting. It is hormonally regulated, stimulated by insulin and inhibited by growth hormone and leptin. SREB- 1 and PPAR- $\gamma$ are the major transcriptional regulators of this process and mediate the action of nutrients and hormones [144]. The process of lipolysis is stimulated by fasting, catecholamines, and atrial natriuretic peptide and inhibited by insulin. It is mediated by hormone sensitive lipase (HSL) and adipose triglyceride lipase (ATGL).

The mechanism of adipose tissue lipid balance has been extensively studied from point of view of understanding molecular basis of obesity, inflammation and high free fatty acid flux. Microarray has potential application of identifying molecular pathways underlying physiology of lipid balance of an adipocyte in health and disease. It is also of help in understanding effects of various nutrients, chemical, experimental drugs on fat storage and lipolysis by an adipocyte.

Gene expression profiling using microarray has been applied in understanding differences between small and hypertrophied adipocytes. Jernas et al. [145] compared gene expression profiles of hypertrophied adipocytes with smaller adipocytes obtained from the same individual. 14 genes showed 4-fold upregulation in hypertrophied adipocytes. Five of them were immune related: E-selectin, interleukin
(IL)-8, serum amyloid a (SAA), C1q receptor 1 , and CXCL2 also known as MIP-2 or macrophage inflammatory protein2. SAA is secreted by adipose tissue and is acute phase protein implicated in insulin resistance, adipose tissue macrophage infiltration, and cholesterol reverse transport [146-148]. Therefore, SSA and other proteins could be important mediators of hypertrophied adipocyte in insulin resistance, inflammation, and diabetes. TM4SF1 gene was also upregulated in hypertrophied adipocytes. The precise function of this protein is not known, but speculated to be related to inflammation [149]. This gene was also over-expressed in visceral adipose tissue as well as among obese individuals [150]. It was mapped to the chromosomal region which was also found to be linked with BMI and fasting insulin level among Pima Indians [151]. Therefore these transcriptomic findings support the concept that hypertrophied adipocyte itself induces inflammatory changes in adipose tissue.

Hypertrophied adipocytes also releases large amount of saturated fatty acids. These saturated free fatty acids act as natural ligands for toll-like receptor 4 and activate inflammation in both adipocytes and infiltrating macrophages via nuclear factor kappa $\mathrm{B}(\mathrm{NF}-\kappa \mathrm{B})$ [152]. In a recent study cDNA microarray analysis of saturated fatty-acidstimulated macrophages in vitro and obese adipose tissue in vivo was done by the same group of investigators. They find activating transcription factor (ATF) 3 (a member of the ATF/cAMP response element-binding protein family of basic leucine zipper-type transcription factors) as a target gene of saturated fatty acids/TLR4 signaling in macrophages in obese adipose tissue. Importantly, ATF3, when induced by saturated fatty acids, can transcriptionally repress tumor necrosis factor- $\alpha$ production in macrophages in vitro. Overexpression of ATF3 specifically in macrophages results in the marked attenuation of proinflammatory M1 macrophage activation in the adipose tissue. Therefore it is hypothesized that it could be a negative feedback mechanism that attenuates obesity-induced macrophage activation. Hence activation of ATF3 in macrophages offers a novel therapeutic strategy to prevent or treat obesity-induced adipose tissue inflammation [153].

Some of the recent microarray studies have examined effects of some chemicals on process of lipogenesis and lipolysis. Dietary flavonoid phloretin enhances 3T3-L1 adipocyte differentiation and adiponectin expression at least in part through PPAR- $\gamma$ activation [154]. In a recent microarray study it was shown that phloretin positively regulates the expression of numerous genes involved in lipogenesis and triglyceride storage, including GLUT4, ACSL1, PEPCK1, lipin-1 and perilipin (more than twofold). The expression of several genes encoding adipokines, in addition to adiponectin and its receptor, was positively or negatively regulated in a way that suggests a possible reduction in systemic insulin resistance and obesity-associated inflammation. Improvement of insulin sensitivity was also suggested by the overexpression of genes associated with insulin signal transduction, such as CAP, PDK1 and Akt2. Many of these genes are PPARgamma targets, confirming the involvement of PPARgamma pathway in the phloretin effects on adipocytes [155]. 
Docosahexaenoic acid (DHA) increases lipolysis and decreases lipogenesis. Wang et al. [156] treated human breast adipocytes with hSAA1 (recombinant human serum amyloid A protein) or DHA in vitro. They find that expression of peroxisome proliferator-activated receptor gamma and other lipogenic genes was decreased, whereas the expression of several lipolytic genes was increased. Glycerol release was increased by both SAA and DHA treatments, suggesting that they increased lipolytic activity in human adipocytes. The expression of perilipin, a lipid droplet-protective protein, was decreased, and hormone-sensitive lipase was increased by both of hSAA1 and DHA treatment. They speculated that the mechanism of lipolysis by DHA or SAA is at least partially the result of increased expression of hormonesensitive lipase and decreased expression of perilipin. The finding of this study also suggested that as DHA treatment increased expression of hSAA1 in human adipocytes, the DHA-mediated reduction in expression of lipogenesis genes and enhancement of lipolysis may be through the activity of hSAA1.

\section{Skeletal Muscle and Hepatocyte Transcriptome in Insulin-Resistant States: Role of Cytokines and FFA}

Obesity and insulin resistance is associated with fatty liver disease manifested clinically as increased triglyceride deposition in liver (steatosis) and progressive necroinflammatory liver disease (steatohepatitis, NASH) [157, 158]. Increased FFA flux from adipose tissue in insulin-resistant state is associated with hepatic fat deposition, impairment in mitochondrial energy biogenesis and insulin resistance. It was recently suggested that rather than being an "innocent bystander", liver steatosis may be the "guilty party" of the progression to cirrhosis [159-161] and possibly in the development of hepatocellular carcinoma (HCC) [162]. This can result in end-stage liver disease requiring liver transplantation [163165]. Therefore, understanding the molecular mechanisms underlying FLD is of major importance. Microarray has potential application in understanding molecular basis of fatty liver disease.

Chiappini et al. [166] studied global gene expression in human liver steatosis. They find that mitochondrial alterations play a major role in the development of steatosis. Activation of inflammatory pathways is present at a very early stage of steatosis, even if no morphological sign of inflammation is observed.

Sreekumar et al. [167] compared genomewide transcription profiles in liver biopsies from cirrhotic stage of NASH with cirrhosis caused by hepatitis $\mathrm{C}$ and healthy controls. Sixteen genes were uniquely differentially expressed (4 overexpressed and 12 underexpressed) in patients with cirrhoticstage NASH. Genes that were significantly underexpressed included genes important for maintaining mitochondrial function (copper/zinc superoxide dismutase, aldehyde oxidase, and catalase). Glucose 6-phospatase, alcohol dehydrogenase, elongation factor-TU, methylglutaryl coenzyme A (CoA), acyl CoA synthetase, oxoacyl CoA thiolase, and ubiquitin also were underexpressed in NASH. Genes that were overexpressed in NASH included complement component $\mathrm{C} 3$ and hepatocyte-derived fibrinogen-related protein, potentially contributing to impaired insulin sensitivity. In conclusion, these studies provide evidence for a transcriptional or pretranscriptional basis for impaired mitochondrial function (attenuated capacity for the dismutation of reactive oxygen species) and diminished insulin sensitivity (increased acute phase reactants) in patients with histologically progressive NASH.

Cheung et al. [168] studied differentially expressed micro RNAs, their target in NASH and impact of one specific differentially expressed microRNA, miR122. Total of 23 microRNAs were underexpressed or overexpressed. The predicted targets of these microRNAs are known to affect cell proliferation, protein translation, apoptosis, inflammation, oxidative stress, and metabolism. Underexpression of miR122 potentially contributes to altered lipid metabolism implicated in the pathogenesis of NASH.

Type-2 diabetes is associated with muscle insulin resistance and first-degree relatives of them also have high insulin resistance. There is increasing evidence for a link between insulin resistance and impaired mitochondrial oxidative phosphorylation (OXPHOS) in human skeletal muscle in vivo [169-173]. Several microarray-based studies of skeletal muscle have reported coordinated downregulation of OXPHOS genes (mitochondrial biogenesis) in patients with type 2 diabetes and high-risk individuals [174-177], that reduced expression of the genes encoding transcriptional coactivator peroxisome proliferator-activated receptor $\gamma$ coactivator $1 \alpha$ (PGC-1 $\alpha)$ and nuclear respiratory factor 1 (NRF1) could play a key role in these transcriptional changes [175-177].

However, it is an important question one need to answer is whether, skeletal muscle insulin resistance is a primary genetic defect or secondary to high FFA flux and cytokines secreted from visceral adipose tissue. Frederiksen et al. [178] generated transcriptional profiling of myotubes from patients with type 2 diabetes mellitus and obese control subjects. They find that no single gene was differently expressed after correction for multiple testing, and no biological pathway was differentially expressed using global pathway analysis. In particular, they found no evidence for differential expression of genes involved in mitochondrial oxidative metabolism. Consistently, there was no difference in mRNA levels of genes known to mediate the transcriptional control of mitochondrial biogenesis (PPARGC1A and NRF1) or in mitochondrial mass between diabetic and control myotubes. Hence the results of this study support the hypothesis that impaired mitochondrial biogenesis is not a primary defect in the sequence of events leading to insulin resistance and type 2 diabetes. The other meaning of this study is that impaired mitochondrial oxidative phosphorylation (OXPHOS) in skeletal muscle is possibly reversible with control of hyperglycemia and dysmetabolism. Sreekumar et al. [174] studied gene expression profile in the skeletal muscle of patients with type 2 diabetes while not on treatment for 2 weeks and after 10 days of intensive insulin treatment. Of 6,451 genes surveyed, transcriptional patterns of 85 genes 
showed alterations in the diabetic patients after withdrawal of treatment, when compared with patterns in the nondiabetic control subjects. Insulin treatment reduced the difference in patterns between diabetic and nondiabetic control subjects (improved) in all but 11 gene transcripts, which included genes involved in structural and contractile functions: growth and tissue development, stress response, and energy metabolism. These improved transcripts included genes involved in insulin signaling, transcription factors, and mitochondrial maintenance. However, insulin treatment altered the transcription of 29 additional genes involved in signal transduction; structural and contractile functions; growth and tissue development; protein, fat, and energy metabolism. Therefore they identified several candidate genes playing role in muscle insulin resistance, complications associated with poor glycemic control, and effects of insulin treatment in people with type 2 diabetes.

Yang et al. [179] compared muscle transcription profiles of equally obese high- and low-insulin-resistant individuals. The authors concluded that 185 differentially expressed transcripts, 20 per cent were true positives and some could generate new hypotheses about the aetiology or pathophysiology of insulin-resistance. Furthermore, differentially expressed genes in chromosomal regions with linkage to diabetes and insulin-resistance serve as new diabetes susceptible genes.

Nguyen et al. performed gene expression profiling on skeletal muscle of insulin-resistant and insulin-sensitive subjects using microarrays. Microarray analysis of 19,000 genes in skeletal muscle did not display a significant difference between insulin-resistant and insulin sensitive muscle. This was confirmed with real-time PCR. These results suggest that insulin resistance is not reflected by changes in the gene expression profile in skeletal muscle [180].

\section{Effect of Caloric Restriction, Drugs, and Chemical Toxins on Adipose Tissue Transcriptome}

There are several reports in the literature studying the effect of various factors such as nutrition, stress, and drugs, on gene expression profile of adipose tissue in animal models, in vitro cell lines and occasionally in human beings.

Dahlman et al. [181] investigated the effect of different low-energy diets on gene expression in human adipose tissue. They find that macronutrients have a secondary role in changes in adipocyte gene expression after energy-restricted diets. The most striking alteration after energy restriction is a coordinated reduction in the expression of genes regulating the production of polyunsaturated fatty acids.

Capel et al. [182] studied effect of calorie restriction, weight stabilization on insulin sensitivity, and subcutaneous adipose tissue gene expression profile. They find that adipose tissue macrophages and adipocytes show distinct patterns of gene regulation and association with insulin sensitivity during the various phases of a dietary weight loss program. They concluded that macrophage and fat cell gene expressions in adipose tissue are differentially regulated during the calorie restriction and weight maintenance phases of a weight loss program. The diet-induced improvement of insulin sensitivity is associated with changes in clusters of genes rather than in single genes, with the sets of genes being different in each phase of the program. The kinetics of changes within adipose tissue and the interactions between the metabolic state of adipocytes and the activation state of macrophages appear critical for the understanding of the beneficial effects on health resulting from a long-term dietary weight loss program in obese subjects. Clément et al. [183] studied changes in subcutaneous adipose tissue gene expression profiles after feeding with very low calorie diet for 28 days. They find that weight loss improves the inflammatory profile of obese subjects through a decrease of proinflammatory factors and an increase of antiinflammatory molecules. The genes are expressed mostly in the stromavascular fraction of adipose tissue, which is shown to contain numerous macrophages. The beneficial effect of weight loss on obesity-related complications may be associated with the modification of the inflammatory profile in adipose tissue. Viguerie et al. [184] determined the levels of transcripts for 38 genes that are expressed in adipose tissue and encode transcription factors, enzymes, transporters and receptors known to play critical roles in the regulation of adipogenesis, mitochondrial respiration, lipid, and carbohydrate metabolism in two groups of 25 obese subjects following 10-week hypocaloric diet programmes with either $20-25$ or $40-45 \%$ of total energy derived from fat being investigated. Levels of mRNA were measured by performing real-time RT-PCR on subcutaneous fat samples obtained from the subjects before and after the diets. Ten genes were regulated by energy restriction; however, none of the genes showed a significantly different response to the diets. Levels of peroxisome proliferator-activated receptor gamma coactivator 1alpha mRNA were increased, while the expression of the genes encoding leptin, osteonectin, phosphodiesterase $3 \mathrm{~B}$, hormone-sensitive lipase, receptor $\mathrm{A}$ for natriuretic peptide, fatty acid translocase, lipoprotein lipase, uncoupling protein 2 and peroxisome proliferatoractivated receptor gamma was decreased. In accordance with the comparable loss of fat mass produced by the two diets, this study shows that energy restriction and/or weight loss rather than the ratio of fat: carbohydrate in a low-energy diet is of importance in modifying the expression of genes in the human adipose tissue. Kolehmainen et al. [185] find that weight reduction in subjects with metabolic syndrome was associated with strong down regulation of genes regulating extracellular matrix and cell death.

van Dijk et al. [186] investigated the effect of a saturated fatty acid-(SFA-) and a monounsaturated fatty acid(MUFA-) rich diet on insulin sensitivity, serum lipids, and gene expression profiles of adipose tissue in subjects at risk of metabolic syndrome. They find that consumption of an SFA diet resulted in a proinflammatory "obesitylinked" gene expression profile, whereas consumption of a MUFA diet caused a more anti-inflammatory profile. This suggests that replacement of dietary SFA with MUFA could prevent adipose tissue inflammation and may reduce the risk of inflammation-related diseases such as metabolic syndrome. 
Dietary supplementation of arginine is the physiologic precursor of nitric oxide (NO), and its dietary supplementation has potential to reduce the fat mass. Fu et al. [187] studied effect of arginine supplementation on fat mass and underlying molecular mechanisms in Zucker diabetic fatty (ZDF) rat, a genetically obese animal model of type II diabetes mellitus. They find that arginine supplementation increased adipose tissue expression of key genes responsible for fatty acid and glucose oxidation: NO synthase1 (145\%), heme oxygenase-3 (789\%), AMP-activated protein kinase $(123 \%)$, and peroxisome proliferator-activated receptor gamma coactivator-1alpha (500\%). Their findings suggest that arginine treatment may provide a potentially novel and useful means to enhance NO synthesis and reduce fat mass in obese subjects with type II diabetes mellitus. Arginine treatment may provide a potentially novel and useful means to enhance NO synthesis and reduce fat mass in obese subjects with type-II diabetes mellitus. Another study by Jobgen et al. [188] also showed that high fat diet and arginine supplementation differentially regulate gene expression to affect energy-substrate oxidation, redox state, fat accretion, and adipocyte differentiation in adipose tissue. Their findings provide a molecular mechanism to explain a beneficial effect of arginine on ameliorating diet-induced obesity in mammals.

Molecular mechanisms underlying metabolic effects of nutritional factors like calorie, fat, arginine, vitamin C, grape anthocyanins and so forth, were understood in human beings and animal models. There are isolated reports about the effects of several factors like stress, dihydrotestosterone, lipocalin 2, rosiglitazone, licorice flavonoids, Turmeric oleoresin, coca, topiramate, leptin, $\beta$-adrenoceptor agonists, and so forth, in animal models, cell lines and occasionally in humans [189-193].

\section{Molecular Basis of Differences between Visceral and Subcutaneous Fat: Transcriptional Evidences}

Association of visceral obesity with increased expression of cytokines/adipokines and hormones mediating insulin resistance suggest that these two depots of fat are not mere different locations of same tissue, rather biologically different organs with different molecular functions. It is also possible that they differ in their origin during embryonic life [194]. Microarray is an important and appropriate tool for studying differences in gene function between visceral and subcutaneous adipose tissue. Several studies have compared transcriptomes of these two tissues. Ramis et al. [195] compared transcriptomes of visceral and subcutaneous tissues and reconfirmed by RT-PCR differential expression of the two best candidates, carboxypeptidase E (CPE), and thrombospondin-1 (THBS1) (EST N72406). They find that both genes appeared to be strongly differentially expressed, having a higher expression in the visceral depot than in the subcutaneous. For THBS1, the difference in expression between the depots was greater in women than in men. The involvement of CPE and THBS1 in obesity suggests that the physiological processes controlled by these genes contribute to depot and gender-related differences in the metabolic complications of obesity. Dolinková et al. [196] evaluated expression profile of genes potentially related to metabolic complications of obesity in the whole adipose tissue and isolated adipocytes from subcutaneous (SAT) and visceral adipose tissue (VAT) from 12 nondiabetic obese women and 12 lean women. They found increased expression of specific proinflammatory and adipogenic genes and reduced expression of specific lipogenic and insulin signaling pathway genes in obese relative to lean women with no preferable localization in SAT or VAT depot. The gene expression significantly differed between adipocytes and adipose tissue but both contributed to the proinflammatory profile in obesity. They conclude that both SAT and VAT exhibit alterations in the expression of specific genes possibly contributing to proinflammatory and insulin resistance state and consequently to metabolic complications of obesity.

\section{Genetics of Gene Expression: Integration of Gene Expression, Genotype, and Clinical Phenotype}

Currently there are two major genomic strategies for identification of genes underlying complex diseases. The first strategy is finding the gene sequence variants associated with clinical phenotype [197]. Genomewide association studies using genomewide SNP markers with diabetes and related phenotypes have been quite successful in identification of genomic regions having diabetes susceptibility genes [198]. However, limitations of these studies do not provide any information about function of these genes and the mechanisms involved in pathogenesis of disease. The other strategy is identification of network of coexpressed genes perturbed in the insulin-resistant state by gene expression profiling. However, gene expression profiling does not provide any information on drivers of disease, and causal information. Association studies of gene expression phenotypes identify gene sequence variants regulating gene function and when combined with clinical information could infer causal association between expression and disease trait [199]. Identification of gene networks that are perturbed by susceptibility loci for a given clinical trait could refine definition of the trait, identify disease subtypes, construct gene networks associated with the disease and identify key drivers of disease [200-205]. Data on this type of investigations in human adiposopathy is lacking. However, in segregating mouse population resulted in the identification of a macrophage-enriched network supported as having a causal relationship with disease traits associated with metabolic syndrome [206].

\section{Clinical Applications}

There are several potential applications of gene expression profiling in clinical practice like finding the new molecular targets of drug development based on molecular mechanisms underlying insulin resistance, classification of insulin resistance into subtypes, molecular diagnostic markers of future 
insulin resistance in early life, and prediction of therapeutic response or adverse effects on the basis of transcription profiles [207-209]. At present gene expression profiling has not percolated to clinical practice and is only a research tool. Several molecular mechanisms identified by microarray like those underlying adipogenesis and inflammation mediated by adipose tissue macrophage infiltration have potential to serve new molecular target of drug discovery. PPAR- $\gamma$ and its agonists are best example of this clinical application. Similarly, Integration of molecular profiling with genotype and clinical traits and identification of DNA polymorphs which are drivers of insulin resistance associated transcription profiles has potential application in classification of adiposity into pathogenic and benign fat [210]. More drastic life-style modification and drug therapy to prevent insulin resistance will be advised in individuals having pathologic adipose tissue even before they gain weight and develop insulin resistance.

\section{Limitations of Microarray}

Despite power (i.e., genomewide scale) and multiple applications in understanding molecular functions of cell (level of gene and protein expression, genomewide association with SNP markers and copy number variants, RNA splicing, gene methylation, microRNA study, etc.) there are limitations of microarray in understanding molecular basis of insulin resistance. These limitations are both of microarray technology itself and its application in understanding insulin resistance.

In contrast to gene sequence, transcriptome depends on cell type and its environmental conditions; therefore large amount of data is generated which is analyzed by different methods. Also there is no standardized unit of estimation of gene expression; hence data is only presented as fold change. There are no known uniform standard gene expression levels for every cell in the body underphysiologic conditions, so that true assessment of gene expression in pathophysiologic conditions is impossible [211]. More overdata generated by using different platforms, arrays, and methods of normalization has produced inconsistent data for same type of experiment performed in different labs $[128,212,213]$. Most of the genes prioritized to be differentially expressed in adipose tissue, muscle tissue, and so forth, in any study were not replicated in subsequent study. Lastly molecular functions identified by transcriptomic profile could not be reconfirmed by other methods [213].

In addition to limitations of microarray technology itself, there are many more constrains in its application in understanding molecular functions of muscle, liver, and adipose tissue in insulin resistance. Insulin resistance is a continuous parameter and clinically identified on criteria which have no pathophysiologic basis (i.e., metabolic syndrome). Precise labeling of insulin resistance and its true control is difficult because it is function of adipose tissue mass and location (visceral or subcutaneous) and quality (good or bad fat). Moreover transciptome also depends on the associated conditions like infection, stress, hyperglycemia, and several drugs used to treat clinical conditions like diabetes (metformin, glitazones, telmisartan, etc.). The method of obtaining tissue also influences gene expression (needle versus open adipose tissue biopsy) [214].

\section{Conclusion}

Despite several limitations microarray has proved a valuable tool in understanding obesity insulin resistance relationship. There is need to standardize the technique and overcome the problems of lack of validation and nonreplication. Integration of expression profiling with clinical phenotypes and genotyping has potential to open avenues for its clinical application like classification of obesity, molecular diagnosis and newer therapeutic options.

\section{References}

[1] S. Del Prato, R. C. Bonadonna, E. Bonora et al., "Characterization of cellular defects of insulin action in type 2 (noninsulin-dependent) diabetes mellitus," Journal of Clinical Investigation, vol. 91, no. 2, pp. 484-494, 1993.

[2] G. M. Reaven, "Role of insulin resistance in human disease," Diabetes, vol. 37, no. 12, pp. 1595-1607, 1988.

[3] G. M. Reaven, "Pathophysiology of insulin resistance in human disease," Physiological Reviews, vol. 75, no. 3, pp. 473486, 1995.

[4] M. Koffler, L. C. Ramirez, and P. Raskin, "Insulin resistance and diabetes, mechanism and possible intervention," Diabetes Research and Clinical Practice, vol. 7, no. 2, pp. 83-98, 1989.

[5] J. Vague, "The degree of masculine differentiation of obesities: a factor determining predisposition to diabetes, atherosclerosis, gout, and uric calculous disease," The American Journal of Clinical Nutrition, vol. 4, no. 1, pp. 20-34, 1956.

[6] E. S. Ford, "Prevalence of the metabolic syndrome defined by the international diabetes federation among adults in the U.S," Diabetes Care, vol. 28, no. 11, pp. 2745-2749, 2005.

[7] R. J. Adams, S. Appleton, D. H. Wilson et al., "Population comparison of two clinical approaches to the metabolic syndrome: implications of the new International Diabetes Federation consensus definition," Diabetes Care, vol. 28, no. 11, pp. 2777-2779, 2005.

[8] E. S. Ford, W. H. Giles, and A. H. Mokdad, "Increasing prevalence of the metabolic syndrome among U.S. adults," Diabetes Care, vol. 27, no. 10, pp. 2444-2449, 2004.

[9] G. Reaven, "The metabolic syndrome or the insulin resistance syndrome? Different names, different concepts, and different goals," Endocrinology and Metabolism Clinics of North America, vol. 33, no. 2, pp. 283-303, 2004.

[10] R. Kahn, J. Buse, E. Ferrannini, and M. Stern, “The metabolic syndrome: time for a critical appraisal-joint statement from the American Diabetes Association and the European Association for the Study of Diabetes," Diabetes Care, vol. 28, no. 9, pp. 2289-2304, 2005.

[11] D. C. W. Lau, "Metabolic syndrome: perception or reality?" Current Atherosclerosis Reports, vol. 11, no. 4, pp. 264-271, 2009.

[12] S. H. Kim and G. M. Reaven, "The metabolic syndrome: one step forward, two steps back," Diabetes \& Vascular Disease Research, vol. 1, no. 2, pp. 68-75, 2004. 
[13] G. M. Reaven, "The metabolic syndrome: Is this diagnosis necessary?" American Journal of Clinical Nutrition, vol. 83, no. 6, pp. 1237-1247, 2006.

[14] H. E. Bays, J. M. González-Campoy, R. R. Henry et al., "Is adiposopathy (sick fat) an endocrine disease?" International Journal of Clinical Practice, vol. 62, no. 10, pp. 1474-1483, 2008.

[15] H. Bays and C. A. Dujovne, "Adiposopathy is a more rational treatment target for metabolic disease than obesity alone," Current Atherosclerosis Reports, vol. 8, no. 2, pp. 144-156, 2006.

[16] H. Bays, "Adiposopathy: role of adipocyte factors in a new paradigm," Expert Review of Cardiovascular Therapy, vol. 3, no. 2, pp. 187-189, 2005.

[17] C. H. Andreasen and G. Andersen, "Gene-environment interactions and obesity-further aspects of genomewide association studies," Nutrition, vol. 25, no. 10, pp. 998-1003, 2009.

[18] J. Vockley, "Metabolism as a complex genetic trait, a systems biology approach: Implications for inborn errors of metabolism and clinical diseases," Journal of Inherited Metabolic Disease, vol. 31, no. 5, pp. 619-629, 2008.

[19] L. O. Schulz, P. H. Bennett, E. Ravussin et al., "Effects of traditional and western environments on prevalence of type 2 diabetes in Pima Indians in Mexico and the U.S," Diabetes Care, vol. 29, no. 8, pp. 1866-1871, 2006.

[20] R. G. Nelson, M. L. Sievers, W. C. Knowler et al., "Low incidence of fatal coronary heart disease in Pima Indians despite high prevalence of non-insulin-dependent diabetes," Circulation, vol. 81, no. 3, pp. 987-995, 1990.

[21] N. Abate, M. Chandalia, P. G. Snell, and S. M. Grundy, "Adipose tissue metabolites and insulin resistance in nondiabetic Asian Indian men," Journal of Clinical Endocrinology and Metabolism, vol. 89, no. 6, pp. 2750-2755, 2004.

[22] M. Chandalia, N. Abate, A. Garg, J. Stray-Gundersen, and S. M. Grundy, "Relationship between generalized and upper body obesity to insulin resistance in Asian Indian men," Journal of Clinical Endocrinology and Metabolism, vol. 84, no. 7, pp. 2329-2335, 1999.

[23] C. Dina, "New insights into the genetics of body weight," Current Opinion in Clinical Nutrition and Metabolic Care, vol. 11, no. 4, pp. 378-384, 2008.

[24] D. Pomp, D. Nehrenberg, and D. Estrada-Smith, "Complex genetics of obesity in mouse models," Annual Review of Nutrition, vol. 28, pp. 331-345, 2008.

[25] T. Joy and R. A. Hegele, "Genetics of Metabolic syndrome: is there a role for phenomics?" Current Atherosclerosis Reports, vol. 10, no. 3, pp. 201-208, 2008.

[26] A. G. Comuzzie, J. T. Williams, L. J. Martin, and J. Blangero, "Searching for genes underlying normal variation in human adiposity," Journal of Molecular Medicine, vol. 79, no. 1, pp. 57-70, 2001.

[27] T. F. C. MacKay, E. A. Stone, and J. F. Ayroles, "The genetics of quantitative traits: challenges and prospects," Nature Reviews Genetics, vol. 10, no. 8, pp. 565-577, 2009.

[28] W. Cookson, L. Liang, G. Abecasis, M. Moffatt, and M. Lathrop, "Mapping complex disease traits with global gene expression," Nature Reviews Genetics, vol. 10, no. 3, pp. 184194, 2009.

[29] C. Buechler and A. Schäffler, "Does global gene expression analysis in type 2 diabetes provide an opportunity to identify highly promising drug targets?" Endocrine, Metabolic and Immune Disorders-Drug Targets, vol. 7, no. 4, pp. 250-258, 2007.
[30] P. A. Permana, A. Del Parigi, and P. A. Tataranni, "Microarray gene expression profiling in obesity and insulin resistance," Nutrition, vol. 20, no. 1, pp. 134-138, 2004.

[31] S. T. Nadler and A. D. Attie, "Please pass the chips: genomic insights into obesity and diabetes," Journal of Nutrition, vol. 131, no. 8, pp. 2078-2081, 2001.

[32] C. Weyer, J. E. Foley, C. Bogardus, P. A. Tataranni, and R. E. Pratley, "Enlarged subcutaneous abdominal adipocyte size, but not obesity itself, predicts type II diabetes independent of insulin resistance," Diabetologia, vol. 43, no. 12, pp. 14981506, 2000.

[33] B. G. Marques, D. B. Hausman, and R. J. Martin, "Association of fat cell size and paracrine growth factors in development of hyperplastic obesity," American Journal of Physiology, vol. 275, no. 6, pp. R1898-R1908, 1998.

[34] J. Smith, M. Al-Amri, P. Dorairaj, and A. Sniderman, "The adipocyte life cycle hypothesis," Clinical Science, vol. 110, no. 1, pp. 1-9, 2006.

[35] P. Arner, "Regional adipocity in man," Journal of Endocrinology, vol. 155, no. 2, pp. 191-192, 1997.

[36] I. Raz, R. Eldor, S. Cernea, and E. Shafrir, "Diabetes: insulin resistance and derangements in lipid metabolism. Cure through intervention in fat transport and storage," Diabetes/Metabolism Research and Reviews, vol. 21, no. 1, pp. 3-14, 2005.

[37] P. Arner, "Regional differences in protein production by human adipose tissue," Biochemical Society Transactions, vol. 29, no. 2, pp. 72-75, 2001.

[38] I. J. Bujalska, S. Kumar, and P. M Stewart, "Does central obesity reflect 'Cushing's disease of the omentum '?" Lancet, vol. 349, no. 9060, pp. 1210-1213, 1997.

[39] M. C. Carr and J. D. Brunzell, "Abdominal obesity and dyslipidemia in the metabolic syndrome: Importance of type 2 diabetes and familial combined hyperlipidemia in coronary artery disease risk," Journal of Clinical Endocrinology and Metabolism, vol. 89, no. 6, pp. 2601-2607, 2004.

[40] J. P. Després, "Intra-abdominal obesity: an untreated risk factor for Type 2 diabetes and cardiovascular disease," Journal of Endocrinological Investigation, vol. 29, no. 3, pp. 77-82, 2006.

[41] R. N. Bergman, S. P. Kim, K. J. Catalano et al., "Why visceral fat is bad: mechanisms of the metabolic syndrome," Obesity, vol. 14, supplement 1, pp. 16S-19S, 2006.

[42] S. M. Grundy, "Obesity, metabolic syndrome, and cardiovascular disease," Journal of Clinical Endocrinology and Metabolism, vol. 89, no. 6, pp. 2595-2600, 2004.

[43] S. P. Weisberg, D. McCann, M. Desai, M. Rosenbaum, R. L. Leibel, and A. W. Ferrante, "Obesity is associated with macrophage accumulation in adipose tissue," Journal of Clinical Investigation, vol. 112, no. 12, pp. 1796-1808, 2003.

[44] H. Xu, G. T. Barnes, Q. Yang et al., "Chronic inflammation in fat plays a crucial role in the development of obesity-related insulin resistance," Journal of Clinical Investigation, vol. 112, no. 12, pp. 1821-1830, 2003.

[45] U. Kintscher, M. Hartge, K. Hess et al., "T-lymphocyte infiltration in visceral adipose tissue: a primary event in adipose tissue inflammation and the development of obesitymediated insulin resistance," Arteriosclerosis, Thrombosis, and Vascular Biology, vol. 28, no. 7, pp. 1304-1310, 2008.

[46] C. M. Smas and H. S. Sul, "Control of adipocyte differentiation," Biochemical Journal, vol. 309, no. 3, pp. 697-710, 1995.

[47] S. R. Farmer, "Transcriptional control of adipocyte formation," Cell Metabolism, vol. 4, no. 4, pp. 263-273, 2006. 
[48] G. J. Hausman, J. T. Wright, and R. L. Richardson, "The influence of extracellular matrix substrata on preadipocyte development in serum-free cultures of stromal-vascular cells," Journal of Animal Science, vol. 74, no. 9, pp. 2117-2128, 1996.

[49] J. E. Rundhaug, "Matrix metalloproteinases and angiogenesis," Journal of cellular and molecular medicine, vol. 9, no. 2, pp. 267-285, 2005.

[50] J. Lilla, D. Stickens, and Z. Werb, "Metalloproteases and adipogenesis: a weighty subject," American Journal of Pathology, vol. 160, no. 5, pp. 1551-1554, 2002.

[51] J. M. Argilés, J. López-Soriano, V. Almendro, S. Busquets, and F. J. López-Soriano, "Cross-talk between skeletal muscle and adipose tissue: a link with obesity?" Medicinal Research Reviews, vol. 25, no. 1, pp. 49-65, 2005.

[52] T. J. Bartness, C. K. Song, H. Shi, R. R. Bowers, and M. T. Foster, "Brain-adipose tissue cross talk," Proceedings of the Nutrition Society, vol. 64, no. 1, pp. 53-64, 2005.

[53] P. Storz, H. Döppler, A. Wernig, K. Pfizenmaier, and G. Müller, "Cross-talk mechanisms in the development of insulin resistance of skeletal muscle cells. Palmitate rather than tumour necrosis factor inhibits insulin-dependent protein kinase B (PKB)/AKT stimulation and glucose uptake," European Journal of Biochemistry, vol. 266, no. 1, pp. 17-25, 1999.

[54] C. M. Smas and H. S. Sul, "Control of adipocyte differentiation," Biochemical Journal, vol. 309, no. 3, pp. 697-710, 1995.

[55] H. Bays, L. Mandarino, and R. A. DeFronzo, "Role of the adipocyte, free fatty acids, and ectopic fat in pathogenesis of Type 2 diabetes mellitus: peroxisomal proliferator-activated receptor agonists provide a rational therapeutic approach," Journal of Clinical Endocrinology and Metabolism, vol. 89, no. 2, pp. 463-478, 2004.

[56] L. Heilbronn, S. R. Smith, and E. Ravussin, "Failure of fat cell proliferation, mitochondrial function and fat oxidation results in ectopic fat storage, insulin resistance and type II diabetes mellitus," International Journal of Obesity, vol. 28, supplement 4, pp. S12-S21, 2004.

[57] S. P. Weisberg, D. McCann, M. Desai, M. Rosenbaum, R. L. Leibel, and A. W. Ferrante Jr., "Obesity is associated with macrophage accumulation in adipose tissue," Journal of Clinical Investigation, vol. 112, no. 12, pp. 1796-1808, 2003.

[58] J. N. Fain, S. W. Bahouth, and A. K. Madan, "TNF $\alpha$ release by the nonfat cells of human adipose tissue," International Journal of Obesity, vol. 28, no. 4, pp. 616-622, 2004.

[59] J. N. Fain, D. S. Tichansky, and A. K. Madan, "Most of the interleukin 1 receptor antagonist, cathepsin S, macrophage migration inhibitory factor, nerve growth factor, and interleukin 18 release by explants of human adipose tissue is by the non-fat cells, not by the adipocytes," Metabolism, vol. 55, no. 8, pp. 1113-1121, 2006.

[60] D. Patsouris, P. P. Li, D. Thapar, J. Chapman, J. M. Olefsky, and J. G. Neels, "Ablation of CD11c-positive cells normalizes insulin sensitivity in obese insulin resistant animals," Cell Metabolism, vol. 8, no. 4, pp. 301-309, 2008.

[61] J. M. Wentworth, G. Naselli, W. A. Brown et al., "Proinflammatory $\mathrm{CD} 11 \mathrm{c}^{+} \mathrm{CD} 206^{+}$adipose tissue macrophages are associated with insulin resistance in human obesity," Diabetes, vol. 59, no. 7, pp. 1648-1656, 2010.

[62] H. Bays and C. Ballantyne, "Adiposopathy: why do adiposity and obesity cause metabolic disease?” Future Lipidology, vol. 1, no. 4, pp. 389-420, 2006.
[63] Wood I. S. and P. Trayhurn, "Adipokines and the signaling role of adipose tissue in inflammation and obesity," Future Lipidology, vol. 1, no. 1, pp. 81-89, 2006.

[64] L. Lionetti, M. P. Mollica, A. Lombardi, G. Cavaliere, G. Gifuni, and A. Barletta, "From chronic overnutrition to insulin resistance: the role of fat-storing capacity and inflammation," Nutrition, Metabolism and Cardiovascular Diseases, vol. 19, no. 2, pp. 146-152, 2009.

[65] T. Suganami, J. Nishida, and Y. Ogawa, "A paracrine loop between adipocytes and macrophages aggravates inflammatory changes: role of free fatty acids and tumor necrosis factor $\alpha$," Arteriosclerosis, Thrombosis, and Vascular Biology, vol. 25, no. 10, pp. 2062-2068, 2005.

[66] M. Chee, R. Yang, E. Hubbell et al., "Accessing genetic information with high-density DNA arrays," Science, vol. 274, no. 5287, pp. 610-614, 1996.

[67] A. S. Ishkanian, C. A. Malloff, S. K. Watson et al., "A tiling resolution DNA microarray with complete coverage of the human genome," Nature Genetics, vol. 36, no. 3, pp. 299-303, 2004.

[68] D. Gresham, M. J. Dunham, and D. Botstein, "Comparing whole genomes using DNA microarrays," Nature Reviews Genetics, vol. 9, no. 4, pp. 291-302, 2008.

[69] Y. Kim and T. Park, "DNA microarrays to define and search for genes associated with obesity," Biotechnology Journal, vol. 5, no. 1, pp. 99-112, 2010.

[70] S. T. Nadler, J. P. Stoehr, K. L. Schueler, G. Tanimoto, B. S. Yandell, and A. D. Attie, "The expression of adipogenic genes is decreased in obesity and diabetes mellitus," Proceedings of the National Academy of Sciences of the United States of America, vol. 97, no. 21, pp. 11371-11376, 2000.

[71] J. Gómez-Ambrosi, V. Catalán, A. Diez-Caballero et al., "Gene expression profile of omental adipose tissue in human obesity," The FASEB Journal, vol. 18, no. 1, pp. 215-217, 2004.

[72] U. N. Das and A. A. Rao, "Gene expression profile in obesity and type 2 diabetes mellitus," Lipids in Health and Disease, vol. 6, article 35, 2007.

[73] F. E. Von Eyben, J. P. Kroustrup, J. F. Larsen, and J. Celis, "Comparison of gene expression in intra-abdominal and subcutaneous fat: a study of men with morbid obesity and nonobese men using microarray and proteomics," Annals of the New York Academy of Sciences, vol. 1030, pp. 508-536, 2004.

[74] A. Baranova, R. Collantes, S. J. Gowder et al., "Obesityrelated differential gene expression in the visceral adipose tissue," Obesity Surgery, vol. 15, no. 6, pp. 758-765, 2005.

[75] I. Dahlman and P. Arner, "Obesity and polymorphisms in genes regulating human adipose tissue," International Journal of Obesity, vol. 31, no. 11, pp. 1629-1641, 2007.

[76] Y. H. Lee, S. Nair, E. Rousseau et al., "Microarray profiling of isolated abdominal subcutaneous adipocytes from obese vs non-obese Pima Indians: increased expression of inflammation-related genes," Diabetologia, vol. 48, no. 9, pp. 1776-1783, 2005.

[77] S. Nair, Y. H. Lee, E. Rousseau et al., "Increased expression of inflammation-related genes in cultured preadipocytes/stromal vascular cells from obese compared with non-obese Pima Indians," Diabetologia, vol. 48, no. 9, pp. 1784-1788, 2005.

[78] C. Darimont, O. Avanti, F. Blancher et al., "Contribution of mesothelial cells in the expression of inflammatory-related factors in omental adipose tissue of obese subjects," International Journal of Obesity, vol. 32, no. 1, pp. 112-120, 2008. 
[79] M. Jernås, J. Palming, K. Sjöholm et al., "Separation of human adipocytes by size: hypertrophic fat cells display distinct gene expression," The FASEB Journal, vol. 20, no. 9, pp. 1540-1542, 2006.

[80] S. K. Mathur, P. Chandra, S. Mishra, P. Ajmera, and P. Sharma, "Type-2 diabetes related intermediate phenotypic traits in north Indian diabetics," Indian Journal of Clinical Biochemistry, vol. 22, no. 2, pp. 70-73, 2007.

[81] R. Shah, Y. Lu, C. C. Hinkle et al., "Gene profiling of human adipose tissue during evoked inflammation in vivo," Diabetes, vol. 58, no. 10, pp. 2211-2219, 2009.

[82] U. Kintscher, M. Hartge, K. Hess et al., "T-lymphocyte infiltration in visceral adipose tissue: a primary event in adipose tissue inflammation and the development of obesitymediated insulin resistance," Arteriosclerosis, Thrombosis, and Vascular Biology, vol. 28, no. 7, pp. 1304-1310, 2008.

[83] M. E. Rausch, S. Weisberg, P. Vardhana, and D. V. Tortoriello, "Obesity in C57BL/6J mice is characterized by adipose tissue hypoxia and cytotoxic T-cell infiltration," International Journal of Obesity, vol. 32, no. 3, pp. 451-463, 2008.

[84] H. Wu, S. Ghosh, X. D. Perrard et al., "T-cell accumulation and regulated on activation, normal $\mathrm{T}$ cell expressed and secreted upregulation in adipose tissue in obesity," Circulation, vol. 115, no. 8, pp. 1029-1038, 2007.

[85] C. N. Lumeng, J. L. Bodzin, and A. R. Saltiel, "Obesity induces a phenotypic switch in adipose tissue macrophage polarization," Journal of Clinical Investigation, vol. 117, no. 1, pp. 175-184, 2007.

[86] L. K. Heilbronn and L. V. Campbell, "Adipose tissue macrophages, low grade inflammation and insulin resistance in human obesity," Current Pharmaceutical Design, vol. 14, no. 12, pp. 1225-1230, 2008.

[87] J. M. Olefsky and C. K. Glass, "Macrophages, inflammation, and insulin resistance," Annual review of physiology, vol. 72, pp. 219-246, 2010.

[88] A. O’Hara, F. L. Lim, D. J. Mazzatti, and P. Trayhurn, "Microarray analysis identifies matrix metalloproteinases (MMPs) as key genes whose expression is up-regulated in human adipocytes by macrophage-conditioned medium," Pflugers Archiv European Journal of Physiology, vol. 458, no. 6, pp. 1103-1114, 2009.

[89] M. E. Rausch, S. Weisberg, P. Vardhana, and D. V. Tortoriello, "Obesity in C57BL/6J mice is characterized by adipose tissue hypoxia and cytotoxic T-cell infiltration," International Journal of Obesity, vol. 32, no. 3, pp. 451-463, 2008.

[90] P. Trayhurn, B. Wang, and I. S. Wood, "Hypoxia in adipose tissue: a basis for the dysregulation of tissue function in obesity?" British Journal of Nutrition, vol. 100, no. 2, pp. 227235, 2008.

[91] N. Hosogai, A. Fukuhara, K. Oshima et al., "Adipose tissue hypoxia in obesity and its impact on adipocytokine dysregulation," Diabetes, vol. 56, no. 4, pp. 901-911, 2007.

[92] B. Wang, I. S. Wood, and P. Trayhurn, "Dysregulation of the expression and secretion of inflammation-related adipokines by hypoxia in human adipocytes," Pflugers Archiv European Journal of Physiology, vol. 455, no. 3, pp. 479-492, 2007.

[93] G. B. Di Gregorio, A. Yao-Borengasser, N. Rasouli et al., "Expression of CD68 and macrophage chemoattractant protein-1 genes in human adipose and muscle tissues: association with cytokine expression, insulin resistance, and reduction by pioglitazone," Diabetes, vol. 54, no. 8, pp. 23052313, 2005.
[94] H. Sell and J. Eckel, "Monocyte chemotactic protein-1 and its role in insulin resistance," Current Opinion in Lipidology, vol. 18, no. 3, pp. 258-262, 2007.

[95] P. Sartipy and D. J. Loskutoff, "Monocyte chemoattractant protein 1 in obesity and insulin resistance," Proceedings of the National Academy of Sciences of the United States of America, vol. 100, no. 12, pp. 7265-7270, 2003.

[96] A. Chen, S. Mumick, C. Zhang et al., "Diet induction of monocyte chemoattractant protein-1 and its impact on obesity," Obesity Research, vol. 13, no. 8, pp. 1311-1320, 2005.

[97] C. A. Curat, A. Miranville, C. Sengenès et al., "From blood monocytes to adipose tissue-resident macrophages: induction of diapedesis by human mature adipocytes," Diabetes, vol. 53, no. 5, pp. 1285-1292, 2004.

[98] J. Huber, F. W. Kiefer, M. Zeyda et al., "CC chemokine and CC chemokine receptor profiles in visceral and subcutaneous adipose tissue are altered in human obesity," Journal of Clinical Endocrinology and Metabolism, vol. 93, no. 8, pp. 3215-3221, 2008.

[99] M. L. Gruen, M. Hao, D. W. Piston, and A. H. Hasty, "Leptin requires canonical migratory signaling pathways for induction of monocyte and macrophage chemotaxis," American Journal of Physiology, vol. 293, no. 5, pp. C1481-C1488, 2007.

[100] Y. Kamei, T. Suganami, T. Ehara et al., "Increased expression of DNA methyltransferase 3a in obese adipose tissue: studies with transgenic mice," Obesity, vol. 18, no. 2, pp. 314-321, 2010.

[101] F. M. Gregoire, C. M. Smas, and H. S. Sul, "Understanding adipocyte differentiation," Physiological Reviews, vol. 78, no. 3, pp. 783-809, 1998.

[102] S. R. Farmer, "Transcriptional control of adipocyte formation," Cell Metabolism, vol. 4, no. 4, pp. 263-273, 2006.

[103] X. Guo and K. Liao, "Analysis of gene expression profile during 3T3-L1 preadipocyte differentiation," Gene, vol. 251, no. 1, pp. 45-53, 2000.

[104] A. Soukas, N. D. Socci, B. D. Saatkamp, S. Novelli, and J. M. Friedman, "Distinct transcriptional profiles of adipogenesis in vivo and in vitro," Journal of Biological Chemistry, vol. 276, no. 36, pp. 34167-34174, 2001.

[105] G. R. Burton, YU. Guan, R. Nagarajan, and R. E. McGehee, "Microarray analysis of gene expression during early adipocyte differentiation," Gene, vol. 293, no. 1-2, pp. 21-31, 2002.

[106] G. R. Burton, R. Nagarajan, C. A. Peterson, and R. E. McGehee, "Microarray analysis of differentiation-specific gene expression during 3T3-L1 adipogenesis," Gene, vol. 329, no. 1-2, pp. 167-185, 2004.

[107] B. A. Jessen and G. J. Stevens, "Expression profiling during adipocyte differentiation of 3T3-L1 fibroblasts," Gene, vol. 299, no. 1-2, pp. 95-100, 2002.

[108] D. L. Gerhold, F. Liu, G. Jiang et al., "Gene expression profile of adipocyte differentiation and its regulation by peroxisome proliferator-activated receptor- $\gamma$ agonists," Endocrinology, vol. 143, no. 6, pp. 2106-2118, 2002.

[109] A. Hsiao, D. S. Worrall, J. M. Olefsky, and S. Subramaniam, "Variance-modeled posterior inference of microarray data: detecting gene-expression changes in 3T3-L1 adipocytes," Bioinformatics, vol. 20, no. 17, pp. 3108-3127, 2004.

[110] J. Gómez-Ambrosi, V. Catalán, A. Diez-Caballero et al., "Gene expression profile of omental adipose tissue in human obesity," The FASEB Journal, vol. 18, no. 1, pp. 215-217, 2004.

[111] H. Hackl, T. R. Burkard, A. Sturn et al., "Molecular processes during fat cell development revealed by gene expression 
profiling and functional annotation," Genome Biology, vol. 6, no. 13, article 108, 2005.

[112] J. Liu, S. M. DeYoung, M. Zhang, M. Zhang, A. Cheng, and A. R. Saltiel, "Changes in integrin expression during adipocyte differentiation," Cell Metabolism, vol. 2, no. 3, pp. 165-177, 2005.

[113] C. Pantoja, J. T. Huff, and K. R. Yamamoto, "Glucocorticoid signaling defines a novel commitment state during adipogenesis in vitro," Molecular Biology of the Cell, vol. 19, no. 10, pp. 4032-4041, 2008.

[114] J. S. Huo, R. C. McEachin, T. X. Cui et al., "Profiles of growth hormone $(\mathrm{GH})$-regulated genes reveal timedependent responses and identify a mechanism for regulation of activating transcription factor 3 by GH," Journal of Biological Chemistry, vol. 281, no. 7, pp. 4132-4141, 2006.

[115] P. Åkerblad, R. Månsson, A. Lagergren et al., "Gene expression analysis suggests that EBF-1 and PPAR $\gamma 2$ induce adipogenesis of NIH-3T3 cells with similar efficiency and kinetics," Physiological Genomics, vol. 23, no. 2, pp. 206-216, 2005.

[116] A. Baudry, Z.-Z. Yang, and B. A. Hemmings, " $\mathrm{PKB} \alpha$ is required for adipose differentiation of mouse embryonic fibroblast," Journal of Cell Science, vol. 119, no. 5, pp. 889897, 2006.

[117] M. Christian, E. Kiskinis, D. Debevec, G. Leonardsson, R. White, and M. G. Parker, "RIP140-targeted repression of gene expression in adipocytes," Molecular and Cellular Biology, vol. 25, no. 21, pp. 9383-9391, 2005.

[118] T. C. Otto, R. R. Bowers, and M. D. Lane, "BMP-4 treatment of C3H10T1/2 stem cells blocks expression of MMP-3 and MMP-13," Biochemical and Biophysical Research Communications, vol. 353, no. 4, pp. 1097-1104, 2007.

[119] Y. H. Tseng, A. J. Butte, E. Kokkotou et al., "Prediction of preadipocyte differentiation by gene expression reveals role of insulin receptor substrates and necdin," Nature Cell Biology, vol. 7, no. 6, pp. 601-611, 2005.

[120] J. A. Timmons, K. Wennmalm, O. Larsson et al., "Myogenic gene expression signature establishes that brown and white adipocytes originate from distinct cell lineages," Proceedings of the National Academy of Sciences of the United States of America, vol. 104, no. 11, pp. 4401-4406, 2007.

[121] S. C. Hung, C. F. Chang, H. L. Ma, T. H. Chen, and L. LowTone Ho, "Gene expression profiles of early adipogenesis in human mesenchymal stem cells," Gene, vol. 340, no. 1, pp. 141-150, 2004.

[122] I. Sekiya, B. L. Larson, J. T. Vuoristo, J. G. Cui, and D. J. Prockop, "Adipogenic differentiation of human adult stem cells from bone marrow stroma (MSCs)," Journal of Bone and Mineral Research, vol. 19, no. 2, pp. 256-264, 2004.

[123] T. Nakamura, S. Shiojima, Y. Hirai et al., "Temporal gene expression changes during adipogenesis in human mesenchymal stem cells," Biochemical and Biophysical Research Communications, vol. 303, no. 1, pp. 306-312, 2003.

[124] M. Scheideler, C. Elabd, L.-E. Zaragosi et al., "Comparative transcriptomics of human multipotent stem cells during adipogenesis and osteoblastogenesis," BMC Genomics, vol. 9, article 340, 2008.

[125] S. Urs, C. Smith, B. Campbell et al., "Gene expression profiling in human preadipocytes and adipocytes by microarray analysis," Journal of Nutrition, vol. 134, no. 4, pp. 762-770, 2004.

[126] P. K. Tan, T. J. Downey, E. L. Spitznagel et al., "Evaluation of gene expression measurements from commercial microarray platforms," Nucleic Acids Research, vol. 31, no. 19, pp. 56765684, 2003.
[127] M. Severgnini, S. Bicciato, E. Mangano et al., "Strategies for comparing gene expression profiles from different microarray platforms: application to a case-control experiment," Analytical Biochemistry, vol. 353, no. 1, pp. 43-56, 2006.

[128] L. Shi, L. H. Reid, W. D. Jones et al., "The MicroArray Quality Control (MAQC) project shows inter- and intraplatform reproducibility of gene expression measurements," Nature Biotechnology, vol. 24, no. 9, pp. 1151-1161, 2006.

[129] K. Birsoy, Z. Chen, and J. Friedman, "Transcriptional regulation of adipogenesis by KLF4," Cell Metabolism, vol. 7, no. 4, pp. 339-347, 2008.

[130] Z. Chen, J. I. Torrens, A. Anand, B. M. Spiegelman, and J. M. Friedman, "Krox20 stimulates adipogenesis via C/EBP $\beta$ dependent and -independent mechanisms," Cell Metabolism, vol. 1, no. 2, pp. 93-106, 2005.

[131] L. C. Chao, S. J. Bensinger, C. J. Villanueva, K. Wroblewski, and P. Tontonoz, "Inhibition of adipocyte differentiation by Nur77, Nurr1, and Nor1," Molecular Endocrinology, vol. 22, no. 12, pp. 2596-2608, 2008.

[132] W. S. Au, V. A. Payne, S. O’Rahilly, and J. J. Rochford, “The NR4A family of orphan nuclear receptors are not required for adipogenesis," International Journal of Obesity, vol. 32, no. 2, pp. 388-392, 2008.

[133] T. Fumoto, T. Yamaguchi, F. Hirose, and T. Osumi, "Orphan nuclear receptor Nur77 accelerates the initial phase of adipocyte differentiation in 3T3-L1 cells by promoting mitotic clonal expansion," Journal of Biochemistry, vol. 141, no. 2, pp. 181-192, 2007.

[134] S. E. Ross, R. L. Erickson, I. Gerin et al., "Microarray analyses during adipogenesis: understanding the effects of Wnt signaling on adipogenesis and the roles of liver $\mathrm{X}$ receptor $\alpha$ in adipocyte metabolism," Molecular and Cellular Biology, vol. 22, no. 16, pp. 5989-5999, 2002.

[135] J. B. Seo, H. M. Moon, W. S. Kim et al., "Activated liver $\mathrm{X}$ receptors stimulate adipocyte differentiation through induction of peroxisome proliferator-activated receptor $\gamma$ expression," Molecular and Cellular Biology, vol. 24, no. 8, pp. 3430-3444, 2004.

[136] M. A. Jimenez, P. Åkerblad, M. Sigvardsson, and E. D. Rosen, "Critical role for Ebf1 and Ebf2 in the adipogenic transcriptional cascade," Molecular and Cellular Biology, vol. 27, no. 2, pp. 743-757, 2007.

[137] Q. Tong, G. Dalgin, H. Xu, C. N. Ting, J. M. Leiden, and G. S. Hotamisligil, "Function of GATA transcription factors in preadipocyte-adipocyte transition," Science, vol. 290, no. 5489, pp. 134-138, 2000.

[138] A. Jeltsch, "Beyond Watson and Crick: DNA methylation and molecular enzymology of DNA methyltransferases," ChemBioChem, vol. 3, no. 4, pp. 275-293, 2002.

[139] T. Horii, S. Morita, M. Kimura, and I. Hatada, "Epigenetic regulation fo adipocyte differetiation by a Rho guanine nucleotide exchange factor, WGEF," PLoS One, vol. 4, no. 6, Article ID e5809, 2009.

[140] Y. Okada, H. Sakaue, T. Nagare, and M. Kasuga, "Dietinduced up-regulation of gene expression in adipocytes without changes in DNA methylation," Kobe Journal of Medical Sciences, vol. 54, no. 5, pp. E241-E249, 2008.

[141] N. Nakanishi, Y. Nakagawa, N. Tokushige et al., "The upregulation of microRNA-335 is associated with lipid metabolism in liver and white adipose tissue of genetically obese mice," Biochemical and Biophysical Research Communications, vol. 385, no. 4, pp. 492-496, 2009. 
[142] T. Sun, M. Fu, A. L. Bookout, S. A. Kliewer, and D. J. Mangelsdorf, "MicroRNA let-7 regulates 3T3-L1 adipogenesis," Molecular Endocrinology, vol. 23, no. 6, pp. 925-931, 2009.

[143] N. A. Ducharme and P. E. Bickel, "Lipid droplets in lipogenesis and lipolysis," Endocrinology, vol. 149, no. 3, pp. 942-949, 2008.

[144] S. Kersten, "Mechanisms of nutritional and hormonal regulation of lipogenesis," EMBO Reports, vol. 2, no. 4, pp. 282-286, 2001.

[145] M. Jernås, J. Palming, K. Sjöholm et al., "Separation of human adipocytes by size: hypertrophic fat cells display distinct gene expression," FASEB Journal, vol. 20, no. 9, pp. E832-E839, 2006.

[146] K. Sjöholm, J. Palming, L. E. Olofsson et al., "A microarray search for genes predominantly expressed in human omental adipocytes: adipose tissue as a major production site of serum amyloid A," Journal of Clinical Endocrinology and Metabolism, vol. 90, no. 4, pp. 2233-2239, 2005.

[147] S. B. Su, W. Gong, JI. L. Gao et al., "A seven-transmembrane, G protein-coupled receptor, FPRL1, mediates the chemotactic activity of serum amyloid A for human phagocytic cells," Journal of Experimental Medicine, vol. 189, no. 2, pp. 395402, 1999.

[148] J. A. Stonik, A. T. Remaley, S. J. Demosky, E. B. Neufeld, A. Bocharov, and H. B. Brewer, "Serum Amyloid a promotes ABCA1-dependent and ABCA1-independent lipid efflux from cells," Biochemical and Biophysical Research Communications, vol. 321, no. 4, pp. 936-941, 2004.

[149] M. Cortés-Canteli, M. Wagner, W. Ansorge, and A. Pérez-Castillo, "Microarray analysis supports a role for CCAAT/enhancer-binding protein- $\beta$ in brain injury," Journal of Biological Chemistry, vol. 279, no. 14, pp. 14409-14417, 2004.

[150] B. G. Gabrielsson, J. M. Johansson, M. Lönn et al., "High expression of complement components in omental adipose tissue in obese men," Obesity Research, vol. 11, no. 6, pp. 699708, 2003

[151] R. E. Pratley, D. B. Thompson, M. Prochazka et al., "An autosomal genomic scan for loci linked to prediabetic phenotypes in pima indians," Journal of Clinical Investigation, vol. 101, no. 8, pp. 1757-1764, 1998.

[152] T. Suganami, K. Tanimoto-Koyama, J. Nishida et al., "Role of the Toll-like receptor $4 / \mathrm{NF}-\kappa \mathrm{B}$ pathway in saturated fatty acid-induced inflammatory changes in the interaction between adipocytes and macrophages," Arteriosclerosis, Thrombosis, and Vascular Biology, vol. 27, no. 1, pp. 84-91, 2007.

[153] T. Suganami, X. Yuan, Y. Shimoda et al., "Activating transcription factor 3 constitutes a negative feedback mechanism that attenuates saturated fatty Acid/Toll-like receptor 4 signaling and macrophage activation in obese adipose tissue," Circulation Research, vol. 105, no. 1, pp. 25-32, 2009.

[154] M. Hassan, C. E. Yazidi, J. F. Landrier, D. Lairon, A. Margotat, and M. J. Amiot, "Phloretin enhances adipocyte differentiation and adiponectin expression in 3T3-L1 cells," Biochemical and Biophysical Research Communications, vol. 361, no. 1, pp. 208-213, 2007.

[155] M. Hassan, C. E. Yazidi, C. Malezet-Desmoulins, M. J. Amiot, and A. Margotat, "Gene expression profiling of 3T3L1 adipocytes exposed to phloretin," Journal of Nutritional Biochemistry, vol. 21, no. 7, pp. 645-652, 2010.

[156] Y. C. Wang, W. H. Kuo, C. Y. Chen et al., "Docosahexaenoic acid regulates serum amyloid A protein to promote lipolysis through down regulation of perilipin," Journal of Nutritional Biochemistry, vol. 21, no. 4, pp. 317-324, 2010.

[157] A. E. Reid, "Nonalcoholic steatohepatitis," Gastroenterology, vol. 121, no. 3, pp. 710-723, 2001.

[158] A. M. Diehl, "Nonalcoholic steatohepatitis," Seminars in Liver Disease, vol. 19, no. 2, pp. 221-230, 1999.

[159] E. E. Powell, W. G. E. Cooksley, R. Hanson, J. Searle, J. W. Halliday, and L. W. Powell, "The natural history of nonalcoholic steatohepatitis: a follow-up study of forty-two patients for up to 21 years," Hepatology, vol. 11, no. 1, pp. 74-80, 1990.

[160] E. M. Brunt, C. G. Janney, A. M. Di Bisceglie, B. A. Neuschwander-Tetri, and B. R. Bacon, "Nonalcoholic steatohepatitis: a proposal for grading and staging the histological lesions," American Journal of Gastroenterology, vol. 94, no. 9, pp. 2467-2474, 1999.

[161] C. A. Matteoni, Z. M. Younossi, T. Gramlich, N. Boparai, Y. C. Liu, and A. J. McCullough, "Nonalcoholic fatty liver disease: a spectrum of clinical and pathological severity," Gastroenterology, vol. 116, no. 6, pp. 1413-1419, 1999.

[162] E. Bugianesi, N. Leone, E. Vanni et al., "Expanding the natural history of nonalcoholic steatohepatitis: from cryptogenic cirrhosis to hepatocellular carcinoma," Gastroenterology, vol. 123, no. 1, pp. 134-140, 2002.

[163] S. H. Caldwell, D. H. Oelsner, J. C. Iezzoni, E. E. Hespenheide, E. H. Battle, and C. J. Driscoll, "Cryptogenic cirrhosis: clinical characterization and risk factors for underlying disease," Hepatology, vol. 29, no. 3, pp. 664-669, 1999.

[164] A. Poonawala, S. P. Nair, and P. J. Thuluvath, "Prevalence of obesity and diabetes in patients with cryptogenic cirrhosis: a case-control study," Hepatology, vol. 32, no. 4, pp. 689-692, 2000.

[165] J. Ong, Z. M. Younossi, V. Reddy et al., "Cryptogenic cirrhosis and posttransplantation nonalcoholic fatty liver disease," Liver Transplantation, vol. 7, no. 9, pp. 797-801, 2001.

[166] F. Chiappini, A. Barrier, R. Saffroy et al., "Exploration of global gene expression in human liver steatosis by highdensity oligonucleotide microarray," Laboratory Investigation, vol. 86, no. 2, pp. 154-165, 2006.

[167] R. Sreekumar, B. Rosado, D. Rasmussen, and M. Charlton, "Hepatic gene expression in histologically progressive nonalcoholic steatohepatitis," Hepatology, vol. 38, no. 1, pp. 244$251,2003$.

[168] O. Cheung, P. Puri, C. Eicken et al., "Nonalcoholic steatohepatitis is associated with altered hepatic MicroRNA expression," Hepatology, vol. 48, no. 6, pp. 1810-1820, 2008.

[169] D. E. Kelley, J. He, E. V. Menshikova, and V. B. Ritov, "Dysfunction of mitochondria in human skeletal muscle in type 2 diabetes," Diabetes, vol. 51, no. 10, pp. 2944-2950, 2002.

[170] V. B. Schrauwen-Hinderling, M. E. Kooi, M. K. C. Hesselink et al., "Impaired in vivo mitochondrial function but similar intramyocellular lipid content in patients with type 2 diabetes mellitus and BMI-matched control subjects," Diabetologia, vol. 50, no. 1, pp. 113-120, 2007.

[171] V. B. Ritov, E. V. Menshikova, J. He, R. E. Ferrell, B. H. Goodpaster, and D. E. Kelley, "Deficiency of subsarcolemmal mitochondria in obesity and type 2 diabetes," Diabetes, vol. 54, no. 1, pp. 8-14, 2005.

[172] R. Boushel, E. Gnaiger, P. Schjerling, M. Skovbro, R. Kraunsøe, and F. Dela, "Patients with type 2 diabetes have normal mitochondrial function in skeletal muscle," Diabetologia, vol. 50, no. 4, pp. 790-796, 2007. 
[173] M. Mogensen, K. Sahlin, M. Fernström et al., "Mitochondrial respiration is decreased in skeletal muscle of patients with type 2 diabetes," Diabetes, vol. 56, no. 6, pp. 1592-1599, 2007.

[174] R. Sreekumar, P. Halvatsiotis, J. C. Schimke, and K. Sreekumaran Nair, "Gene expression profile in skeletal muscle of type 2 diabetes and the effect of insulin treatment," Diabetes, vol. 51, no. 6, pp. 1913-1920, 2002.

[175] M. E. Patti, A. J. Butte, S. Crunkhorn et al., "Coordinated reduction of genes of oxidative metabolism in humans with insulin resistance and diabetes: potential role of PGC1 and NRF1," Proceedings of the National Academy of Sciences of the United States of America, vol. 100, no. 14, pp. 8466-8471, 2003.

[176] V. K. Mootha, C. M. Lindgren, K. F. Eriksson et al., "PGC$1 \alpha$-responsive genes involved in oxidative phosphorylation are coordinately downregulated in human diabetes," Nature Genetics, vol. 34, no. 3, pp. 267-273, 2003.

[177] V. Skov, D. Glintborg, S. Knudsen et al., "Reduced expression of nuclear-encoded genes involved in mitochondrial oxidative metabolism in skeletal muscle of insulin-resistant women with polycystic ovary syndrome," Diabetes, vol. 56, no. 9, pp. 2349-2355, 2007.

[178] C. M. Frederiksen, K. Højlund, L. Hansen et al., "Transcriptional profiling of myotubes from patients with type 2 diabetes: no evidence for a primary defect in oxidative phosphorylation genes," Diabetologia, vol. 51, no. 11, pp. 2068-2077, 2008.

[179] X. Yang, R. Pratley, S. Tokraks, C. Bogardus, and P. Permana, "Microarray profiling of skeletal muscle tissues from equally obese, non-diabetic insulin-sensitive and insulin-resistant Pima Indians," Diabetologia, vol. 45, no. 11, pp. 1584-1593, 2002.

[180] L. L. Nguyen, A. D. Kriketos, D. P. Hancock, I. D. Caterson, and G. S. Denyer, "Insulin resistance does not influence gene expression in skeletal muscle," Journal of Biochemistry and Molecular Biology, vol. 39, no. 4, pp. 457-463, 2006.

[181] I. Dahlman, K. Linder, E. A. Nordström et al., "Changes in adipose tissue gene expression with energy-restricted diets in obese women," American Journal of Clinical Nutrition, vol. 81, no. 6, pp. 1275-1285, 2005.

[182] F. Capel, E. Klimčáková, N. Viguerie et al., "Macrophages and adipocytes in human obesity: adipose tissue gene expression and insulin sensitivity during calorie restriction and weight stabilization," Diabetes, vol. 58, no. 7, pp. 1558-1567, 2009.

[183] K. Clément, N. Viguerie, C. Poitou et al., "Weight loss regulates inflammation-related genes in white adipose tissue of obese subjects," FASEB Journal, vol. 18, no. 14, pp. 1657$1669,2004$.

[184] N. Viguerie, H. Vidal, P. Arner et al., "Adipose tissue gene expression in obese subjects during low-fat and high-fat hypocaloric diets," Diabetologia, vol. 48, no. 1, pp. 123-131, 2005.

[185] M. Kolehmainen, T. Salopuro, U. S. Schwab et al., "Weight reduction modulates expression of genes involved in extracellular matrix and cell death: the GENOBIN study," International Journal of Obesity, vol. 32, no. 2, pp. 292-303, 2008.

[186] S. J. van Dijk, E. J. M. Feskens, M. B. Bos et al., "A saturated fatty acid-rich diet induces an obesity-linked proinflammatory gene expression profile in adipose tissue of subjects at risk of metabolic syndrome," American Journal of Clinical Nutrition, vol. 90, no. 6, pp. 1656-1664, 2009.

[187] W. J. Fu, T. E. Haynes, R. Kohli et al., "Dietary L-arginine supplementation reduces fat mass in Zucker diabetic fatty rats," Journal of Nutrition, vol. 135, no. 4, pp. 714-721, 2005.
[188] W. Jobgen, W. J. Fu, H. Gao et al., "High fat feeding and dietary L-arginine supplementation differentially regulate gene expression in rat white adipose tissue," Amino Acids, vol. 37, no. 1, pp. 187-198, 2009.

[189] C. Bolduc, M. Yoshioka, and J. St-Amand, "Transcriptomic characterization of the long-term dihydrotestosterone effects in adipose tissue," Obesity, vol. 15, no. 5, pp. 1107-1132, 2007.

[190] V. Catalán, J. Gómez-Ambrosi, A. Rodríguez et al., "Increased adipose tissue expression of lipocalin-2 in obesity is related to inflammation and matrix metalloproteinase-2 and metalloproteinase-9 activities in humans," Journal of Molecular Medicine, vol. 87, no. 8, pp. 803-813, 2009.

[191] J. Zhang, Y. Wu, Y. Zhang, D. Leroith, D. A. Bernlohr, and $\mathrm{X}$. Chen, "The role of lipocalin 2 in the regulation of inflammation in adipocytes and macrophages," Molecular Endocrinology, vol. 22, no. 6, pp. 1416-1426, 2008.

[192] F. Aoki, S. Honda, H. Kishida et al., "Suppression by licorice flavonoids of abdominal fat accumulation and body weight gain in high-fat diet-induced obese C57BL/6J mice," Bioscience, Biotechnology and Biochemistry, vol. 71, no. 1, pp. 206-214, 2007.

[193] O. Šeda, L. Šedová, O. Oliyarnyk et al., "Pharmacogenomics of metabolic effects of rosiglitazone," Pharmacogenomics, vol. 9, no. 2, pp. 141-155, 2008.

[194] V. Van Harmelen, A. Dicker, M. Rydén et al., "Increased lipolysis and decreased leptin production by human omental as compared with subcutaneous preadipocytes," Diabetes, vol. 51, no. 7, pp. 2029-2036, 2002.

[195] J. M. Ramis, N. L. W. Franssen-van Hal, E. Kramer et al., "Carboxypeptidase E and thrombospondin-1 are differently expressed in subcutaneous and visceral fat of obese subjects," Cellular and Molecular Life Sciences, vol. 59, no. 11, pp. 19601971, 2002.

[196] M. Dolinková, I. Dostálová, Z. Lacinová et al., “The endocrine profile of subcutaneous and visceral adipose tissue of obese patients," Molecular and Cellular Endocrinology, vol. 291, no. 1-2, pp. 63-70, 2008.

[197] P. Sebastiani, N. Timofeev, D. A. Dworkis, T. T. Perls, and M. H. Steinberg, "Genome-wide association studies and the genetic dissection of complex traits," American Journal of Hematology, vol. 84, no. 8, pp. 504-515, 2009.

[198] M. I. McCarthy and E. Zeggini, "Genome-wide association studies in type 2 diabetes," Current Diabetes Reports, vol. 9, no. 2, pp. 164-171, 2009.

[199] R. B. Brem, G. Yvert, R. Clinton, and L. Kruglyak, "Genetic dissection of transcriptional regulation in budding yeast," Science, vol. 296, no. 5568, pp. 752-755, 2002.

[200] V. G. Cheung and R. S. Spielman, "The genetics of variation in gene expression," Nature Genetics, vol. 32, no. 5, pp. 522$525,2002$.

[201] V. G. Cheung, L. K. Conlin, T. M. Weber et al., "Natural variation in human gene expression assessed in lymphoblastoid cells," Nature Genetics, vol. 33, no. 3, pp. 422-425, 2003.

[202] E. E. Schadt, S. A. Monks, T. A. Drake et al., "Genetics of gene expression surveyed in maize, mouse and man," Nature, vol. 422, no. 6929, pp. 297-302, 2003.

[203] R. C. Jansen and J. P. Nap, "Genetical genomics: the added value from segregation," Trends in Genetics, vol. 17, no. 7, pp. 388-391, 2001.

[204] M. Morloy, C. M. Molony, T. M. Weber et al., "Genetic analysis of genome-wide variation in human gene expression," Nature, vol. 430, no. 7001, pp. 743-747, 2004. 
[205] V. G. Cheung, R. S. Spielman, K. G. Ewens, T. M. Weber, M. Morley, and J. T. Burdick, "Mapping determinants of human gene expression by regional and genome-wide association," Nature, vol. 437, no. 7063, pp. 1365-1369, 2005.

[206] Y. Chen, J. Zhu, P. Y. Lum et al., "Variations in DNA elucidate molecular networks that cause disease," Nature, vol. 452, no. 7186, pp. 429-435, 2008.

[207] S. Wang, L. M. Sparks, H. Xie, F. L. Greenway, L. De Jonge, and S. R. Smith, "Subtyping obesity with microarrays: implications for the diagnosis and treatment of obesity," International Journal of Obesity, vol. 33, no. 4, pp. 481-489, 2009.

[208] C. Buechler and A. Schäffler, "Does global gene expression analysis in type 2 diabetes provide an opportunity to identify highly promising drug targets?" Endocrine, Metabolic and Immune Disorders_Drug Targets, vol. 7, no. 4, pp. 250-258, 2007.

[209] S. T. Nadler and A. D. Attie, "Please pass the chips: genomic insights into obesity and diabetes," Journal of Nutrition, vol. 131, no. 8, pp. 2078-2081, 2001.

[210] P. A. Permana, S. Nair, and Y. H. Lee, "Application of DNA microarray to the study of human adipose tissue/cells," Methods in Molecular Biology, vol. 456, pp. 141-154, 2008.

[211] D. Gresham, M. J. Dunham, and D. Botstein, "Comparing whole genomes using DNA microarrays," Nature Reviews Genetics, vol. 9, no. 4, pp. 291-302, 2008.

[212] R. Brandt, R. Grützmann, A. Bauer et al., "DNA microarray analysis of pancreatic malignancies," Pancreatology, vol. 4, no. 6, pp. 587-597, 2004.

[213] G. L. G. Miklos and R. Maleszka, "Microarray reality checks in the context of a complex disease," Nature Biotechnology, vol. 22, no. 5, pp. 615-621, 2004.

[214] D. M. Mutch, J. Tordjman, V. Pelloux et al., "Needle and surgical biopsy techniques differentially affect adipose tissue gene expression profiles," American Journal of Clinical Nutrition, vol. 89, no. 1, pp. 51-57, 2009. 


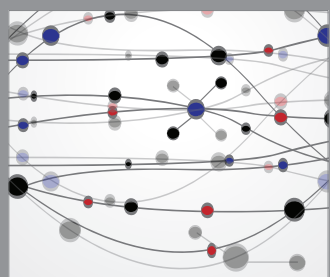

The Scientific World Journal
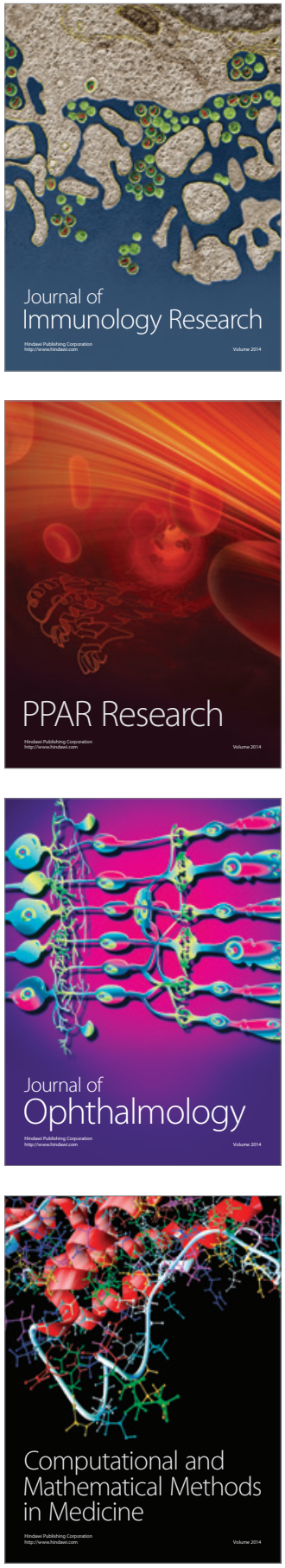

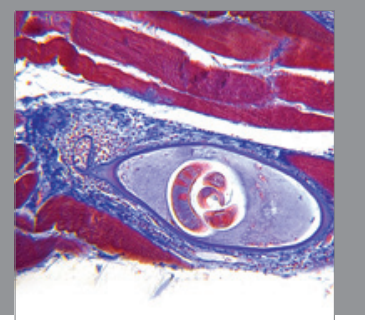

Gastroenterology

Research and Practice
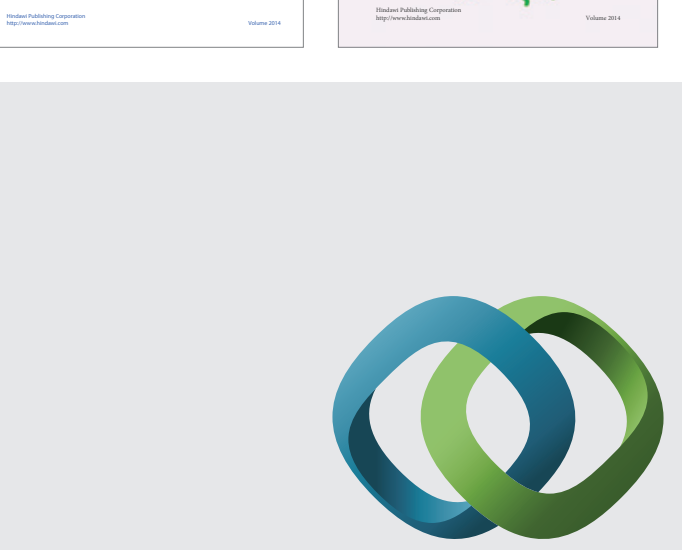

\section{Hindawi}

Submit your manuscripts at

http://www.hindawi.com
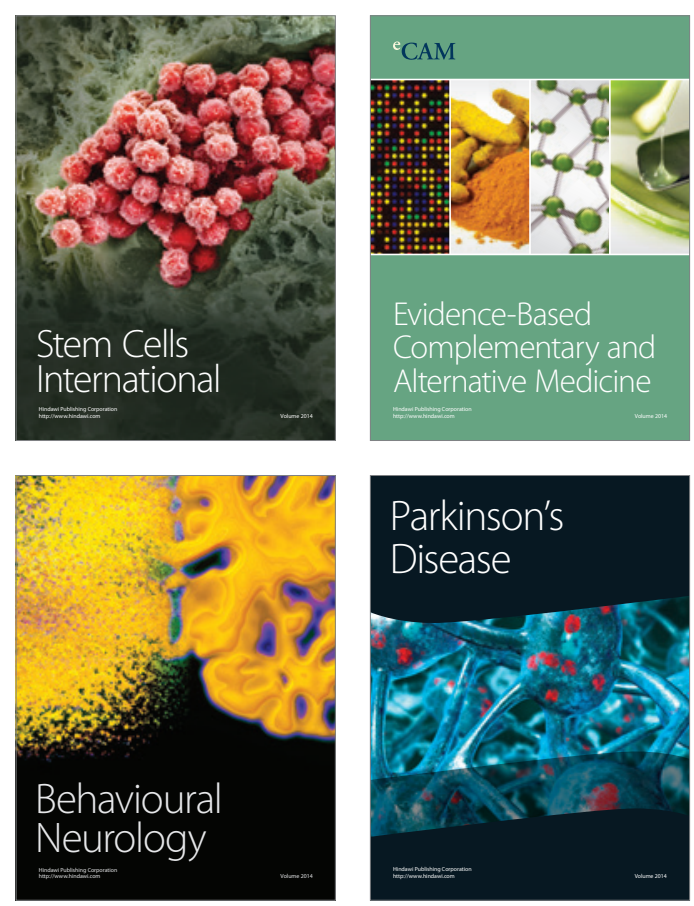

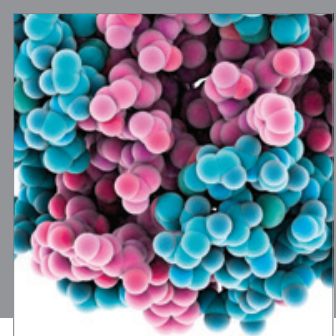

Journal of
Diabetes Research

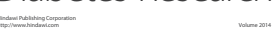

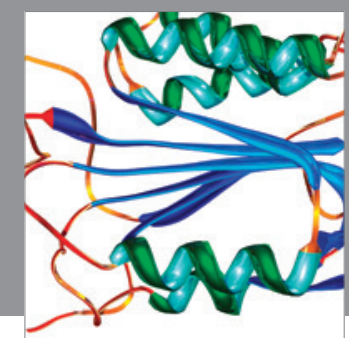

Disease Markers
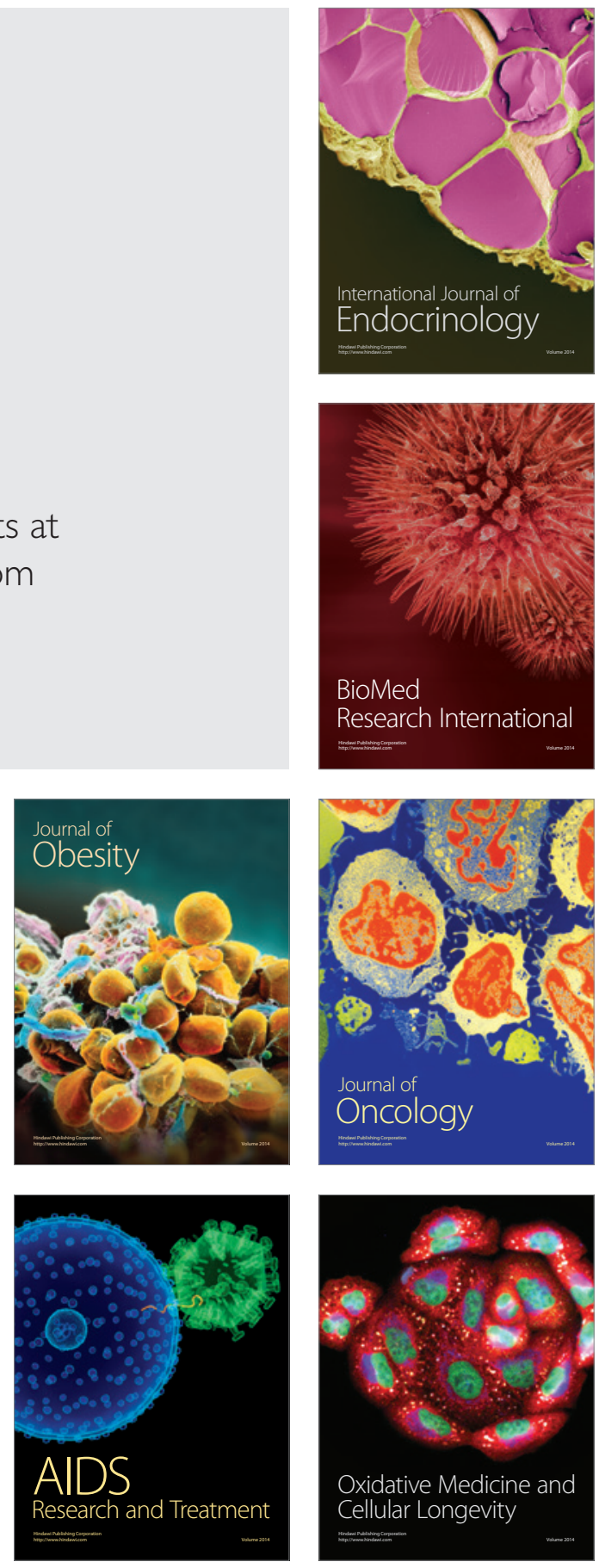